\title{
Market Area Analysis for Retail and Service Locations with MCI
}

by Thomas Wieland

\begin{abstract}
In retail location analysis, marketing research and spatial planning, the market areas of stores and/or locations are a frequent subject. Market area analyses consist of empirical observations and modeling via theoretical and/or econometric models such as the Huff Model or the Multiplicative Competitive Interaction Model. The authors' package MCI implements the steps of market area analysis into $\mathrm{R}$ with a focus on fitting the models and data preparation and processing.
\end{abstract}

\section{Introduction}

A market area (also called trading area, service area or catchment area) is a part of the earth's surface where the actual or potential customers of a supply location come from. This supply location can be any kind of location which provides goods and/or services and generates a geographically segmented market. In retailing, a supply location can be a single store, a retail agglomeration (planned or unplanned shopping centre) or even an entire city (Berman and Evans, 2013; Löffler, 1998).

The market area of a store/location can be regarded as the spatial equivalent to its sum of all customers and/or sales. The total customers/sales of a supply location can be determined by summing the customer flows/expenditures from each geographic region in its market area (Huff and McCallum, 2008; Rodrigue et al., 2006). For practical reasons, a market area can also be divided by zones of market penetration and/or distance/travel time (Berman and Evans, 2013).

Market areas of retail locations result from the consumer spatial shopping behaviour, more precisely, their store choice. Thus, a market area is influenced by many factors such as the transport costs (e.g. distance, travel time) between customers and locations and, of course, the characteristics of the competitors (e.g. perceived "attraction", pricing, image or the opportunity for multi-purpose and comparison shopping). Mostly, the market areas of competing supply locations overlap, which means that they are in spatial competition (Rodrigue et al., 2006; Wieland, 2015a).

Traditionally, market area analysis includes the delineation and segmentation of market areas and can be divided into inductive-empirical and deductive-theoretical approaches. The first type consists of constructing market areas based on empirical observations such as point-of-sale (POS) surveys (customer spotting), while in the latter approach this work is done by using mathematical market area models (Löffler, 1998). Modern market area analyses are mostly a combination of both, especially when using econometric market area models which are fitted by empirical data (Wieland, 2015a).

Market area models can be used in retail location analysis to find new locations, to evaluate the existing outlets or to assess the impact of changes in the competitive landscape (Berman and Evans, 2013; Huff and McCallum, 2008). Market area analyses are also subject of governmental spatial planning in Germany (Wolf, 2012). The econometric models can also be utilized to identify variables influencing consumer decisions and market areas and to check hypotheses about these relations, which means to find out what affects store choice (Wieland, 2015a). The usage of market area models can also be transferred to other service locations, such as health services (Jia et al., 2015).

This paper presents two market area models, the Huff Model and the Multiplicative Competitive Interaction (MCI) Model, and their implementation into R by the authors' package MCI (Wieland, 2016). Yet, only the basic Huff Model formula is integrated in R by the packages SpatialPosition (Giraud and Commenges, 2016), which can be used especially for graphical visualization, and huff-tools (Pavlis et al., 2014), which combines the basic formulation with GIS functions. In contrast, the emphases of the MCI package lie on 1) fitting the MCI Model and the Huff Model via OLS (ordinary least squares) regression and nonlinear techniques, respectively, and 2) the steps of processing and transforming empirical data to be usable in the models (especially working with interaction matrices).

\section{Market area models: theory and application}

Almost all market area models have in common that they are based on an attraction/utility function including transport costs and further characteristics of the supply locations which are subjects of a trade-off by the consumers. The dependent variable of these models is the store choice and/or the choice probability and/or the market shares of the stores/locations (Wieland, 2015a).

The first retail market area models (Reilly, 1929; Converse, 1949) were deterministic, which means that each customer origin is assigned completely to one supply location while overlapping market 
areas are not envisaged. Furthermore only two supply locations can be processed and the explaining variables of the models are not founded theoretically. These gaps were filled by Huff $(1962,1963$, 1964) by introducing his probabilistic market area model. An important content enhancement and, at the same time, an econometric transformation of the Huff Model was introduced in the form of the Multiplicative Competitive Interaction Model by Nakanishi and Cooper $(1974,1982)$.

\section{The Huff Model}

\section{Theoretical background and formulation}

The basis of the Huff Model is the following multiplicative utility function with two explanatory variables representing two determinants of store choice (Huff and Batsell, 1975):

$$
U_{i j}=A_{j}^{\gamma} d_{i j}^{-\lambda}
$$

where $U_{i j}$ is the utility of the supply location $j$ for the customers at origin $i, A_{j}$ reflects the attraction of supply location $j$ and $d_{i j}$ contains the transport costs customers from $i$ have to take to reach $j$. The exponents $\gamma$ and $\lambda$ are weighting parameters.

The attraction is translated as the size of the location due to the increasing probability for a "successful" shopping trip on condition of consumer uncertainty (the greater the locations' offer, the more likely is to get the desired goods). The size is operationalized by the sales area of the locations. But, as the consumers' decision costs normally rise with an increasing number of offered goods, the marginal utility of the locations' offer decreases which is reflected by a degressive weighting of size $(0<\gamma<1)$. The indicator for the transport costs is the travel time from $i$ to $j$, reflecting the time consumed by a shopping trip. To integrate the opportunity costs and the perceived disutility of traveling, the travel time is weighted negatively and progressively $(|\lambda|>1)$ (Huff, 1962).

The parameter $\lambda$ also reflects the range of the offered goods dependent on the shopping frequency: the more high-order the good/less frequently purchased, the less is the disutility of transport costs (Güssefeldt, 2002). But this distance decay function of the power type can also be replaced by an exponential or a logistic function (Kanhäußer, 2007). As suggested by Huff (1962), also the attraction function can be logistic to better reflect the effect of decreasing marginal utility of size.

Derived from the behavioral scientific Luce choice axiom (Luce, 1959), the consumer decision in the Huff Model is regarded as probabilistic. The probability to choose the alternative $j$ from a set of alternatives $(j=1, \ldots, n)$ is the quotient of its utility $U_{i j}$ and the sum of the utilities of all alternatives (Huff, 1962):

$$
p_{i j}=\frac{U_{i j}}{\sum_{j=1}^{n} U_{i j}}=\frac{A_{j}^{\gamma} d_{i j}^{-\lambda}}{\sum_{j=1}^{n} A_{j}^{\gamma} d_{i j}^{-\lambda}},
$$

where $p_{i j}$ is the probability that the customers from origin $i$ travel to location $j$, what can be called interaction probability, where: $\sum_{j=1}^{n} p_{i j}=1$ and $0<p_{i j}<1$. These probabilites can be interpreted as market shares of location $j$ in origin $i$, what can be called local market shares. These shares implicitly represent a final state of consumer preference patterns in a spatial equilibrium (Huff and Batsell, 1975). Thus, in the Huff Model, the revenues of a retail store/location $j$ depend on its own attraction, the attraction of all competitors and the transport costs between all locations and the customer origins.

The expected customer/expenditure flows from $i$ to $j$ are estimated by multiplying the local market shares with the local market potential (Huff, 1962):

$$
E_{i j}=p_{i j} C_{i}
$$

where $E_{i j}$ is the number of expected customer/purchasing power flows from origin $i$ to location $j$ and $C_{i}$ is the total market potential (number of potential customers or purchasing power) in $i$.

The complete market area of location $j$ is the sum of all regional customer or purchasing power flows, while the former represents the total number of customers and the latter equals the total sales of the location, e.g. within a year (Huff, 1964):

$$
T_{j}=\sum_{i=1}^{m} E_{i j}
$$

where $T_{j}$ is the market area of $j$ containing $m$ submarkets, normally measured in persons or money. 


\begin{tabular}{ccccccccc}
\hline $\mathbf{i}$ & $\mathbf{j}$ & $\mathbf{d}_{\mathbf{i j}}$ & $\mathbf{A}_{\mathbf{j}}$ & $\mathbf{U}_{\mathbf{i j}}$ & $\sum \mathbf{U}_{\mathbf{i j}}$ & $\mathbf{p}_{\mathbf{i j}}$ & $\mathbf{C}_{\mathbf{i}}$ & $\mathbf{E}_{\mathbf{i j}}$ \\
\hline$i_{1}$ & $j_{1}$ & $d_{i_{1} j_{1}}$ & $A_{j_{1}}$ & $U_{i_{1} j_{1}}$ & $\sum U_{i_{1}}$ & $p_{i_{1} j_{1}}$ & $C_{i_{1}}$ & $E_{i_{1} j_{1}}$ \\
\hline$i_{1}$ & $j_{2}$ & $d_{i_{1} j_{2}}$ & $A_{j_{2}}$ & $U_{i_{1} j_{2}}$ & $\sum U_{i_{1}}$ & $p_{i_{1} j_{2}}$ & $C_{i_{1}}$ & $E_{i_{1} j_{2}}$ \\
\hline$i_{1}$ & $j_{3}$ & $d_{i_{1} j_{3}}$ & $A_{j_{3}}$ & $U_{i_{1} j_{3}}$ & $\sum U_{i_{1}}$ & $p_{i_{1} j_{3}}$ & $C_{i_{1}}$ & $E_{i_{1} j_{3}}$ \\
\hline$i_{2}$ & $j_{1}$ & $d_{i_{2} j_{1}}$ & $A_{j_{1}}$ & $U_{i_{2} j_{1}}$ & $\sum U_{i_{2}}$ & $p_{i_{2} j_{1}}$ & $C_{i_{2}}$ & $E_{i_{2} j_{1}}$ \\
\hline$i_{2}$ & $j_{2}$ & $d_{i_{2} j_{2}}$ & $A_{j_{2}}$ & $U_{i_{2} j_{2}}$ & $\sum U_{i_{2}}$ & $p_{i_{2} j_{2}}$ & $C_{i_{2}}$ & $E_{i_{2} j_{2}}$ \\
\hline$\ldots$ & $\ldots$ & $\ldots$ & $\ldots$ & $\ldots$ & $\ldots$ & $\ldots$ & $\ldots$ & $\ldots$ \\
\hline$i_{m}$ & $j_{n}$ & $d_{i_{m} j_{n}}$ & $A_{j_{n}}$ & $U_{i_{m} j_{n}}$ & $\sum U_{i_{m}}$ & $p_{i_{m} j_{n}}$ & $C_{i_{m}}$ & $E_{i_{m} j_{n}}$ \\
\hline
\end{tabular}

Table 1: Huff interaction matrix (schematic).

\section{Empirical usage}

While working with the Huff Model, the first step is to delineate the study area itself and to record the focused origins and locations. The explanatory variables must be observed empirically by mapping the regarded stores/locations $\left(A_{j}\right)$ and calculating travel times $\left(d_{i j}\right)$, respectively (Huff, 1962).

All data is stored into a special kind of linear table that is called interaction matrix and is the basis for all further calculation steps (see Table 1). The interaction matrix contains one row for each (potential) spatial interaction between the origins, $i$ (where $i=1, \ldots, m$ ), and the locations, $j$ (where $j=1, \ldots, n)$, so the number of rows sums up to $m * n$. For every row, the utilities and probabilities are calculated using the formulas mentioned above (Wieland, 2015a).

Many approaches were developed to estimate the weighting coefficients by nonlinear iterative techniques. Huff (1962) showed a way to estimate $\lambda$ with a fitting algorithm comparing expected and observed market shares by correlation coefficients while keeping $\gamma$ constantly equal to one. But, if $p_{i j}$, the dependent variable in the Huff Model, was observed, probably the best way to estimate the parameters is the econometric transformation of the model which was achieved by the Multiplicative Competitive Interaction Model by Nakanishi and Cooper (1974) (see the next section).

In many cases, no empirical market shares are available but only observed total sales of stores or locations, $T_{j}$. Thus, many studies focus the model fitting by nonlinear optimization algorithms based on empirical total values (Baecker-Neuchl and Wagenseil, 2015; De Beule et al., 2014; Güssefeldt, 2002; Marinov and Czamanski, 2012; Orpana and Lampinen, 2003; Klein, 1988; Yingru and Lin, 2012). In the following, a new optimization algorithm of this type is introduced which is based on the idea of the local optimization of attraction approach by Güssefeldt (2002) (which is the only one with an explicit theoretical fundament) and features of other mentioned procedures.

\section{A new optimization algorithm for the Huff Model}

Consider a location system with $j$ supply locations (where $j=1, \ldots, n$ ), where $T_{j_{o b s}}$ defines the real (observed) annual sales of $j$. Güssefeldt (2002) argues that every store or location has its own unknown revenue function and the sales (=revenues) depend on its own attraction (=input) and each competitors' behaviour. The attraction variable in the Huff Model, $A_{j}$, is a proxy variable for size (e.g. sales area) reflecting the extent of offers which is the input in the unknown revenue function. But this nonadjusted attraction measure does not reflect the "real" attraction because every competitor modifies the input in his revenue function (e.g. via marketing efforts) without any change in the size variable.

Thus, the expected sales using non-adjusted attractions in the Huff Model, $T_{j_{e x p}}$, do not correspond to the observed sales what can be measured on the local level (which means a single store/location) by the absolute percentage error:

$$
A P E_{j}=\frac{\left|T_{j_{e x p}}-T_{j_{o b s}}\right|}{T_{j_{o b s}}}
$$

where $T_{j_{\text {exp }}}$ is the expected total sales of supply location $j$ (Huff Model result), $T_{j_{o b s}}$ is the observed total sales and $A P E_{j}$ is the absolute percentage error for supply location $j$.

Since the algorithm by Güssefeldt (2002) addresses the local level, there is no fit measure for the global level (which means the model fit for the complete location system). The global model fit can be evaluated in different ways, where three fit measures were already used in the context of optimizing the Huff Model: the mean absolute percentage error (MAPE) and a Pseudo ${ }^{2}$ measure, both used by 
De Beule et al. (2014), and the global error (GE) used by Klein (1988):

$$
M A P E=\frac{1}{N} \sum_{n=1}^{N} \frac{\left|T_{j_{e x p}}-T_{j_{o b s}}\right|}{T_{j_{o b s}}},
$$

where $T_{j_{e x p}}$ is the expected total sales of location $j$ (Huff Model result), $T_{j_{o b s}}$ is the observed total sales and $N$ is the number of objects.

$$
\operatorname{PseudoR} R^{2}=\frac{\operatorname{var}\left(T_{j_{o b s}}\right)-\operatorname{var}\left(\varepsilon_{j}\right)}{\operatorname{var}\left(T_{j_{o b s}}\right)},
$$

where $T_{j_{o b s}}$ is the observed total sales and $\varepsilon_{j}$ is the residuum, $T_{j_{o b s}}-T_{j_{\text {exp }}}$.

$$
G E=\frac{\sum\left|\varepsilon_{j}\right|}{\sum T_{j_{o b s}}}
$$

where $T_{j_{o b s}}$ is the observed total sales and $\varepsilon_{j}$ is the residuum, $T_{j_{o b s}}-T_{j_{\text {exp }}}$.

Since the real sales are known and on condition that the location attraction and the sales are related to each other, the attraction $A_{j}$ can be described as a function of the sales (Güssefeldt, 2002):

$$
A_{j}=a+b T_{j},
$$

where $A_{j}$ is the predicted attraction of location $j, T_{j}$ is the total sales of $j, a$ is the intercept and $b$ is the slope of the attraction function. As every supply location has its own revenue function (each competitor has an individual factor use), the attraction function is also different for each store/location.

On condition that an interval is known, this function can be parametrized by calculating the slope using the difference quotient and the intercept, thereafter (Güssefeldt, 2002). Unlike in the mentioned approach, this function must pass the origin because in the Huff Model with its multiplicative utility function (Formula 1), an attraction equal to zero $\left(A_{j}=0\right)$ must result in an utility equal to zero $\left(U_{i j}=0\right)$ which results in local market shares equal to zero $\left(p_{i j}=0\right.$, Formula 2$)$. Thus, the total sales (Formulae 3 and 4 ) must be equal to zero $\left(T_{j}=0\right)$, too. This is a logical consequence from the theoretical basement of the Huff Model but is also part of the principle of logical consistency of market shares in marketing research (Cooper and Nakanishi, 2010).

Thus, formula 9 has no intercept $(a=0)$ which means a directly proportional relation between sales and attraction. But, as the revenue function differs by each supply location, the attraction function must also be parametrized for each store/location. The slope in the attraction function of location $j$ can be calculated via:

$$
b_{j}=\frac{A_{j}-A_{j_{0}}}{T_{j_{\exp }}-T_{j_{0}}}=\frac{A_{j}}{T_{j_{\text {exp }}}},
$$

where $b_{j}$ is the slope of the attraction function for $j, A_{j}$ is the non-adjusted attraction of location $j$ (such as sales area), $T_{j_{\text {exp }}}$ is the total expected sales of $j$ predicted by the Huff Model, $A_{j_{0}}$ is the attraction when the sales are equal to zero and $T_{j_{0}}$ represents the sales when the attraction is equal to zero, both equal to zero $\left(A_{j}=0 \Leftrightarrow T_{j}=0\right)$. The adjusted attraction of supply location $j$ can be calculated via:

$$
A_{j_{a d j}}=b_{j} T_{j_{o b s}}
$$

where $A_{j_{a d j}}$ is the adjusted attraction of $j, b_{j}$ is the slope of the attraction function for $j$ and $T_{j_{o b s}}$ represents the real (observed) sales of $j$.

The relations mentioned above can be brought together in an optimization algorithm for the Huff Model with respect to a location system with $j$ locations $(j=1, \ldots, n)$ containing the following 8 steps:

1. Set a tolerance value, $t o l_{A P E}$, to define which difference between the real and the expected sales of location $j$ is accepted, e.g. $t o l_{A P E}=5$, which means an accepted deviation of $+/-5$ percent. Define a transport costs weighting function (power, exponential or logistic) and the weighting parameter(s) $\lambda$ for formula 2 .

2. Calculate the market areas for the location system and the total sales of the $n$ locations using formulae 2 to 4 with $\gamma=1$ and the transport costs weighting as defined in step 1 .

3. Calculate the absolute percentage error between the expected and the observed total sales of location $j\left(A P E_{j}\right)$ by formula 5 . If the error $A P E_{j}$ is smaller than the tolerance tol $A P E$, no further local optimization for location $j$ is needed, so you can repeat step 3 with location $j+1$. If $A P E_{j}>$ tol $_{A P E}$, go to step 4 .

4. Calculate the slope of the attraction function by formula 10. Calculate the adjusted attraction via formula 11. 
5. Save the adjusted attraction of location $j, A_{j_{a d j}}$, in the actual Huff interaction matrix and repeat the procedure beginning at step 2 with the next location, $j+1$.

6. Repeat steps 2 to 5 for all locations $(j=1, \ldots, n)$.

7. After the last location $j=n$ was processed, calculate the global fit measures for the complete location system by formulae 6 to 8 .

8. Repeat steps 2 to 7 for the complete location system until the local optima and/or the global optimum is sufficiently approximated. The former can be evaluated by the tolerance value (step 3) for every $j$ location, while the latter can be controlled by the global fit measures (step 7).

\section{The Multiplicative Competitive Interaction (MCI) Model}

\section{Theoretical background and formulation}

The Multiplicative Competitive Interaction Model (in short: MCI Model) is based on the Huff Model but also belongs to the model family of market share models which were developed in marketing science. Thus, it can be regarded as a crossover of these two model families (Cliquet, 2013). The fundamental theorem behind market share models is the following simple relationship between the competitors' characteristics and their market shares (Cooper and Nakanishi, 2010):

$$
M S_{j}=\frac{A_{j}}{\sum_{j=1}^{n} A_{j}},
$$

where $M S_{j}$ is the market share of competitor $j$ and $A_{j}$ is the attraction of $j$. This leads to two characteristics of market shares which are summarized as logical-consistency requirements for market shares: $0<M S_{j}<1$, and $\sum_{j=1}^{n} M S_{j}=1$, respectively (Cooper and Nakanishi, 2010). This market share logic is obviously related to the probabilistic concept of the Huff Model when the term "market shares" is replaced by "choice probabilities", "interaction probabilities" or "local market shares" and the construct "attraction" is replaced by the construct "utility" (Wieland, 2015a).

Derived from the Huff Model, the MCI Model is explicitly formulated to regard a market which is segmented into $i$ submarkets $(i=1, \ldots, m)$ and which is served by $j$ suppliers $(j=1, \ldots, n)$. The attraction function is multiplicative and consists of $h(h=1, \ldots, H)$ explanatory variables which are weighted exponentially to reflect their sensitivity (Nakanishi and Cooper, 1974):

$$
p_{i j}=\frac{\prod_{h=1}^{H} A_{h_{j}}^{\gamma_{h}}}{\sum_{j=1}^{n} \prod_{h=1}^{H} A_{h_{j}}^{\gamma_{h}}},
$$

where $p_{i j}$ is the probability that the customers from submarket $i$ choose supplier $j, A_{h_{j}}$ is the value of the $h$-th variable describing the object $j, \gamma_{h}$ is the weighting parameter for the sensitivity of $p_{i j}$ with respect to the variable $h$. The next steps (customer or expenditure flows, total market area) can be taken analogously to the Huff Model (Formulae 3 and 4).

The market can be subdivided in any kind of submarkets (e.g. customer groups, time periods, geographic areas). When the market is segmented geographically, it is a matter of a Spatial MCI Model, especially when integrating transport costs as an explanatory variable (Cliquet, 2013; Huff and McCallum, 2008). The MCI Model can also be regarded as a generalization of the Huff Model, while the Huff Model can be considered as a special case of multiplicative competitive interaction model.

\section{The log-centering transformation}

The models mentioned above are deterministic (no random variation) and nonlinear models which cannot be estimated directly by common econometric techniques but by iterative algorithms (see the former section) which do not allow statements about the statistical significance of the explanatory variables and other inference statistics. The main breakthrough of the MCI Model is the transformation of the nonlinear structure into a linear stochastic model which can be estimated via OLS (Ordinary Least Squares) regression (Huff and McCallum, 2008).

This requires a re-arrangement of the model to be linear in parameters which is achieved by a multi-step transformation of the variables using geometric means and logarithms for standardization and linearization called the log-centering transformation (Nakanishi and Cooper, 1974):

$$
\log \left(\frac{p_{i j}}{\widetilde{p_{i}}}\right)=\sum_{h=1}^{H} \gamma_{h} \log \left(\frac{A_{h_{j}}}{\widetilde{A_{h_{j}}}}\right)+\log \left(\frac{\varepsilon_{i j}}{\widetilde{\varepsilon_{i}}}\right),
$$


where $\widetilde{p}_{i}$ and $\widetilde{A_{h_{j}}}$ are the geometric means of $p_{i j}$ and $A_{h_{j}}$, respectively, and $\widetilde{\varepsilon_{i}}$ is the geometric mean of the disturbance term (residuum) $\varepsilon_{i j}$ which is added to the original model to be stochastic. The geometric means of $p_{i j}$ and any submarket-related explanatory variable (such as travel time, $d_{i j}$ ) are calculated on the submarket level. As in the original model, the transformation does not include an intercept (regression through the origin) to match the logical-consistency requirements for market shares (Nakanishi and Cooper, 1982).

Once the variables are transformed, the model function is linear in its parameters and can be processed as a multiple linear regression model to be estimated by OLS regression (Rawlings et al., 1998). Thus, the model allows to test hypotheses about the influence of store/location characteristics (such as sales area, pricing) and transport costs (such as travel time, distance) on the local market shares in the submarkets (customer origins) by interpreting the regression coefficients and their inference statistics (Nakanishi and Cooper, 1974, 1982; Huff and McCallum, 2008).

After an estimation of the parameters, they can be included as exponents in the original nonlinear model (Formula 13) to be utilized for market share/market area predictions (Nakanishi and Cooper, 1982; Huff and McCallum, 2008). It is also possible to integrate dummy variables reflecting qualitative information (such as brands or store chains) or an intercept (if necessary). Since the former causes problems in the multiplicative attraction/utility function (multiplication by zero) and the latter is contrary to the logical consistency requirement, a different retransformation of the model called the inverse log-centering transformation is required (Nakanishi and Cooper, 1982):

$$
\begin{gathered}
\hat{y}_{i j}=\sum_{h=1}^{H} \hat{\gamma}_{h} \log \left(\frac{A_{h_{j}}}{\overline{A_{h_{j}}}}\right), \\
\hat{p}_{i j}=\frac{e^{\hat{y}_{i j}}}{\sum_{j=1}^{n} e^{\hat{y}_{i j}}},
\end{gathered}
$$

where $\hat{y}_{i j}$ is the transformed attraction/utility function and $\hat{p}_{i j}$ is the expected response variable, the interaction probabilities/market shares of the supplier $j$ in the submarket $i$. Thus, in that cases, the variables are processed as they were transformed in formula 14.

\section{Empirical usage}

In the first step, a MCI Model analysis requires the formulation of hypotheses and/or research questions addressing the influence of the $H$ explanatory variables on the market shares based on theoretical considerations. The Huff Model can be regarded as a theoretical base since Huff (1962) assumes size and transport costs as explanatory variables which can be tested by the MCI Model (Kubis and Hartmann, 2007; Suárez-Vega et al., 2015). But the number of additional influences tested is nearly unlimited and ranges from further store/location attributes like age or price level (Huff and McCallum, 2008; Tihi and Oruc, 2012) to the surrounding coupling and competition potential (Wieland, 2015a) to consumer-related subjective variables (Cliquet, 2013; González-Benito et al., 2000).

Since the delineation of the study area and the identification of the relevant competing locations have an enormous impact on the results, these definitions should be made corresponding to the LIFO (little in from outside) and LOFI (little out from inside) principles (Huff and McCallum, 2008). This means that the majority of shopping interactions should take place within the study area.

The supplier characteristics can be obtained by mapping the relevant stores/locations and additional research. The market shares, $p_{i j}$, cannot be observed directly but have to be calculated based on empirically observed shopping interactions (shopping trips and/or expenditures) which are collected on the individual or household level. In a representative household survey (or, if not possible, a point-of-sale survey), every respondent is asked for the destination(s) of the last shopping trip(s) at the $j$ location(s) and/or the associated expenditures (Huff and McCallum, 2008; Wieland, 2015a).

To calculate the local market shares of shopping trips and/or expenditures, the individual data must be aggregated on the submarket level:

$$
p_{i j}=\frac{O_{i j}}{\sum_{j=1}^{n} O_{i j}},
$$

where $p_{i j}$ is the empirical market share of supplier $j$ in submarket $i$ and $O_{i j}$ equals the observed frequencies/expenditures of the customers in $i$ with respect to supplier $j . \sum_{j=1}^{n} O_{i j}$ is the empirical equivalent to the total customer/purchasing power potential in $i, C_{i}$, in the Huff Model (formula $3)$. As in the Huff Model, the empirical market shares, $p_{i j}$, and the observed explanatory variables $\left(A_{1}, \ldots, A_{H}, d_{i j}\right)$ are stored in an interaction matrix (see Table 2$)$.

Mostly, the observed variables cannot be processed directly: the log-centering transformation 


\begin{tabular}{ccccccccc}
\hline $\mathbf{i}$ & $\mathbf{j}$ & $\mathbf{p}_{\mathbf{i j}}$ & $\mathbf{A}_{\mathbf{1}_{\mathbf{j}}}$ & $\mathbf{A}_{\mathbf{2}_{\mathbf{j}}}$ & $\mathbf{A}_{\mathbf{3}_{\mathbf{j}}}$ & $\ldots$ & $\mathbf{A}_{\mathbf{H}_{\mathbf{j}}}$ & $\mathbf{d}_{\mathbf{i j}}$ \\
\hline$i_{1}$ & $j_{1}$ & $p_{i_{1} j_{1}}$ & $A_{1_{1}}$ & $A_{2_{1}}$ & $A_{3_{1}}$ & $\ldots$ & $A_{H_{1}}$ & $d_{i_{1} j_{1}}$ \\
\hline$i_{1}$ & $j_{2}$ & $p_{i_{1} j_{2}}$ & $A_{1_{2}}$ & $A_{2_{2}}$ & $A_{3_{2}}$ & $\ldots$ & $A_{H_{2}}$ & $d_{i_{1} j_{2}}$ \\
\hline$i_{1}$ & $j_{3}$ & $p_{i_{1} j_{3}}$ & $A_{1_{3}}$ & $A_{2_{3}}$ & $A_{3_{3}}$ & $\ldots$ & $A_{H_{3}}$ & $d_{i_{1} j_{3}}$ \\
\hline$i_{2}$ & $j_{1}$ & $p_{i_{2} j_{1}}$ & $A_{1_{1}}$ & $A_{2_{1}}$ & $A_{3_{1}}$ & $\ldots$ & $A_{H_{1}}$ & $d_{i_{2} j_{1}}$ \\
\hline$i_{2}$ & $j_{2}$ & $p_{i_{2} j_{2}}$ & $A_{1_{2}}$ & $A_{2_{2}}$ & $A_{3_{2}}$ & $\ldots$ & $A_{H_{2}}$ & $d_{i_{2} j_{2}}$ \\
\hline$\ldots$ & $\ldots$ & $\ldots$ & $\ldots$ & $\ldots$ & $\ldots$ & $\ldots$ & $\ldots$ & $\ldots$ \\
\hline$i_{m}$ & $j_{n}$ & $p_{i_{m} j_{n}}$ & $A_{1_{n}}$ & $A_{2_{n}}$ & $A_{3_{n}}$ & $\ldots$ & $A_{H_{n}}$ & $d_{i_{m} j_{n}}$ \\
\hline
\end{tabular}

Table 2: MCI interaction matrix (schematic).

requires every variable to be ratio-scaled, non-negative and greater than zero. Thus, also market shares equal to zero, $p_{i j}=0$, what may occur, are invalid. A simple way to correct the raw data accepting a small bias is to increase the variable by a small constant (Kubis and Hartmann, 2007; Wieland, 2015a) and/or to aggregate the submarkets (Perales, 2002; Tihi and Oruc, 2012). Anyway, the raw data should be adjusted by removing singular instances and outliers to fulfil the LIFO/LOFI requirements mentioned above (Huff and McCallum, 2008; Wieland, 2015a).

Interval scaled variables (e.g. consumer judgements in rating scales) which may contain negative values can be transformed by the zeta-squared transformation (Cooper and Nakanishi, 1983):

$$
\begin{gathered}
z_{h_{i j}}=\frac{X_{h_{i j}}-\overline{X_{h_{i}}}}{\rho_{h_{i}}}, \\
\zeta_{h_{i j}}^{2}=\left\{\begin{array}{l}
\left(1+z_{h_{i j}}^{2}\right) \text { if } z_{h_{i j}} \geq 0 \\
\left(\frac{1}{1+z_{h_{i j}}^{2}}\right) \text { if } z_{h_{i j}} \leq 0
\end{array}\right.
\end{gathered}
$$

where $z_{h_{i j}}$ is the z-standardized score of $X_{h_{i j}}$ and $\zeta_{h_{i j}}^{2}$ is the zeta-squared value resulting from $z_{h_{i j}}$.

Nominal scaled variables (e.g. store chains, brands) cannot be processed directly in the MCI Model but can be transformed into dummy variables which are ignored in the log-centering transformation.

All in all, an econometric market share/market area analysis using the MCI Model on condition of existing research questions and hypotheses contains the following 8 steps:

1. Define the study area and divide it into $i$ submarkets (here: customer origins).

2. Obtain the relevant variables: shopping trips and/or expenditures on the individual/household level $\left(O_{i j}\right), H$ characteristics of the $j$ regarded suppliers and the transport costs, $d_{i j}$.

3. If necessary, correct or transform the variables to match the requirements of the log-centering transformation: if some $O_{i j}$ or other variables are equal to zero, add a constant, aggregate the submarkets in the study area and remove outliers, respectively. If there are interval scaled variables, transform them by formulae 18 and 19. If there are nominal variables, transform them to dummy variables.

4. Calculate the market shares, $p_{i j}$, by formula 17.

5. Store the submarkets, suppliers, local market shares and the $H$ explanatory variables in an interaction matrix (see Table 2).

6. Apply the log-centering transformation (formula 14) to the previously created interaction matrix.

7. Apply the OLS regression to the log-centering transformed interaction matrix with $\log \left(\frac{p_{i j}}{\bar{p}_{i}}\right)$ as dependent variable treating the model like any other multiple linear regression model: determine the estimators, compute fit measures and inference statistics for the hypothesis tests.

8. Interpret the model results. For market share predictions, insert the estimated parameters in the nonlinear model using formula 13 or formulae 15 and 16.

\section{R implementation}

As outlined in the former section, market area analysis for retail and service locations requires a mixture of descriptive and inference statistics, iterative optimization and, of course, a lot of processing 
and preparation of empirical data which may be even more complex (or, at least, more time-consuming) than the models themselves. Except the Huff Model basis formulation which is implemented in R by the packages SpatialPosition and huff-tools none of the mentioned models were integrated in $\mathrm{R}$ yet. The former mentioned package is focused on graphical visualization and other spatial interaction models while the latter combines the basic Huff formula with GIS-related functions. The Multiplicative Competitive Interaction Model and the related procedures of data handling are just as little integrated in R as the OLS and nonlinear fitting procedures for the Huff Model and the MCI Model, respectively. The motivation of the presented package $\mathbf{M C I}$ is to fill this gap.

\section{The MCI package}

The Huff Model and the Multiplicative Competitive Interaction (MCI) Model are implemented in the MCI package which is focused on:

1. Fitting the mentioned models by empirically observed data using the MCI linearization (logcentering transformation) combined with OLS regression (functions mci.fit(), mci.transmat () and mci. transvar ()) and the Huff Model optimization algorithm described above (functions huff.attrac() and huff.fit()).

2. The steps of data preparation and processing to make empirical data usable in these models, especially the creation and processing of interaction matrices used in MCI analyses which is subject of the function ijmatrix.create().

The MCI package also provides tools that can be used for descriptive analyses of empirical or estimated market areas, such as zoning (see the function shares.segm()) and, of course, the basic Huff and MCI formulations (see the functions mci. shares() and huff. shares(), respectively). The correction of variables to match the MCI requirements can be done by the functions var. correct() and var. asdummy().

The input of the most functions is required to be a "data. frame" where the first function argument is the dataset name, followed by a set of variable names (columns) each one in double quotation marks and further function arguments. Also, the output of nearly every function is a "data.frame", except the mci.fit() function which returns an object of type "lm" and model.fit() which returns a "list". Three functions (huff. decay (), model.fit() and shares. total()) also provide an optional graphical output.

The package does not import any other packages (except some already implemented functions from stats and graphics, of course) and does not contain any non-R scripts.

The data used in the following examples is distributed over several datasets to demonstrate the several data sources and the components of a market area analysis, respectively. In fact, there is no need to split the working data like this, but, of course, it is recommended since the voluminous data may lead to confusion.

\section{Examples}

\section{Analyzing market areas of single locations}

The first example deals with a more descriptive analysis of empirical market areas obtained by a POS survey (customer spotting technique). The package-included example dataset shopping1 is a survey conducted at two supply locations in the east of Karlsruhe, Germany, in May 2016.

The dataset contains 434 surveyed individuals at both locations, including 410 cases from the main survey and 24 cases from the pretest. Amongst other things, the respondents were asked about their place of residence, their shopping preferences in general (last shopping trip with respect to different goods) and their on-site shopping behaviour (duration of stay, expenditures). The customers' origin is stored in the column resid_code. The variable POS indicates the location: "POS1" is a town centre and thus, an evolved retail agglomeration, while "POS2" is an out-of-town planned shopping centre.

It should be noted that a POS survey mostly does not fulfill the requirements of statistical representativity: besides that shopping behaviour differs by weekdays, time periods and, of course, weather, independent from the size and heterogeneity of the sample, the statistical population is unknown.

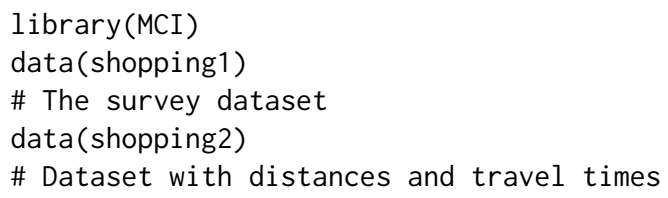


The first step is to filter the dataset since only the interviews are needed which were conducted at both supply locations simultaneously. We subset the relevant data and store it into a new working data frame (shopping1_adj) which we use to create an interaction matrix of type "data.frame" called ijmatrix using the function ijmatrix.create():

shopping1_adj <- shopping1[(shopping1\$weekday != 3) \& (shopping1\$holiday != 1)

\& (shopping1\$survey $!=$ "pretest"),]

\# Removing every case from tuesday, holidays and the ones belonging to the pretest

ijmatrix <- ijmatrix.create(shopping1_adj, "resid_code", "POS", "POS_expen")

\# Creates an interaction matrix based on the observed frequencies (automatically)

\# and the POS expenditures (Variable "POS_expen" separately stated)

ijmatrix

interaction resid_code POS freq_ij_abs freq_i_total p_ij_obs

1 resid1-POS1

2 resid1-POS2 resid1 POS2 $22 \quad 1130.1946903$

3 resid10-POS1 resid10 POS1 30.4285714

$\ldots$

freq_ij_abs_POS_expen freq_i_total_POS_expen p_ij_obs_POS_expen

$\begin{array}{lll}2318.25 & 3245.25 & 0.71435174\end{array}$

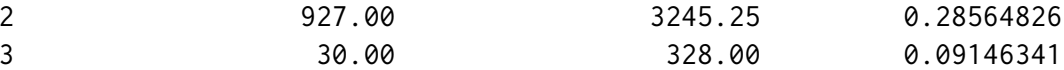

$\cdots$

The resulting data frame (rows 1-3 are displayed) contains the interaction (from each origin to each destination) in the first column (interaction) and each origin and destination in the columns resid_code and POS, respectively, both adopted from the column names in the input dataset. The absolute number of respondents and the total value of expenditures from the origins, $i$, at the destinations, $j$, is stored in freq_ij_abs and freq_ij_abs_POS_expen, respectively. The freq_i_total* columns contain the total number/sum of observed customers/expenditures from each origin, while the $p_{-} i j$ _obs $*$ are the local market shares of customers and expenditures, $p_{i j}$, respectively. The names are set automatically based on the original variable names (e.g. POS_expen).

The next step is the zoning of the empirical market areas by driving time using the function shares. $\operatorname{segm}()$ and the travel time stored in the shopping2 dataset. The routes were calculated in $\mathrm{R}$ using the package ggmap (Kahle and Wickham, 2013). We want to know how much of the customers and expenditures come from origins with a maximal travel time of 10, 20, 30 and more than 30 minutes:

ijmatrix_dist <- merge(ijmatrix, shopping2, by.x = "interaction", by.y = "route", all. $x=$ TRUE)

\# Adding the distances and travel times

visit <- shares.segm(ijmatrix_dist, "resid_code", "POS", "d_time", "freq_ij_abs", $0,10,20,30)$

\# Segmentation by travel time using the number of customers/visitors

\# Parameters: interaction matrix (data frame), columns with origins and destinations,

\# variable to divide in classes, absolute frequencies/expenditures, class segments

expen <- shares.segm(ijmatrix_dist, "resid_code", "POS", "d_time",

"freq_ij_abs_POS_expen", $0,10,20,30$ )

\# Segmentation by travel time using the POS expenditures

visit

$\begin{array}{rrrrr}\text { d_time_class } & \text { POS1_abs } & \text { POS1_rel } & \text { POS2_abs } & \text { POS2_rel } \\ 0-10 & 108 & 72.483221 & 58 & 40.277778 \\ 10-20 & 24 & 16.107383 & 62 & 43.055556 \\ 20-30 & 10 & 6.711409 & 12 & 8.333333 \\ \text { Other } & 7 & 4.697987 & 12 & 8.333333\end{array}$

expen
$\begin{array}{lrrrrr}\text { d_time_class } & \text { POS1_abs } & \text { POS1_rel } & \text { POS2_abs } & \text { POS2_rel } \\ 1 & 0-10 & 2858.25 & 76.418689 & 2900.0 & 34.354491 \\ 2 & 10-20 & 541.00 & 14.464274 & 4052.4 & 48.006255 \\ 3 & 20-30 & 283.00 & 7.566339 & 478.0 & 5.662568 \\ 4 & \text { Other } & 58.00 & 1.550698 & 1011.0 & 11.976686\end{array}$


The "data. frame" output of the used function contains the segment classes, named based on the input variable name (d_time_class), e.g. d_time_class $=" 0-10$ " represents the zone up to 10 minutes of travel time. The further columns contain the sums and the percentage shares for each location, respectively, both named based on the original values (e.g. POS1_abs, POS1_rel).

We see that, at "POS1" (town centre) 108 surveyed customers come from an origin up to 10 minutes of driving time what corresponds to $72.48 \%$ of all customers. At POS2 (out-of-town planned shopping centre), only $40.28 \%$ of the visitors are generated from places of residence where to drive less or equal to 10 minutes. The difference is more clear when looking at the expenditures: at the town centre, $76.42 \%$ of the observed expenditures are spent by customers from origins of the first driving time class, while the share in the corresponding class at the shopping centre is $34.35 \%$.

Since the survey was only conducted at these two supply locations but not at other possible competitive locations, it would not make any sense to use these empirical market areas in an econometric market area model. But, of course, it is possible to analyze the distance decay on the level of single locations.

Before fitting and plotting distance decay functions, some corrections of the data have to be made and, since we don't have local market shares, the dependent variable reflecting the intensity of interaction (surveyed visitors per 1,000 inhabitants) has to be calculated:

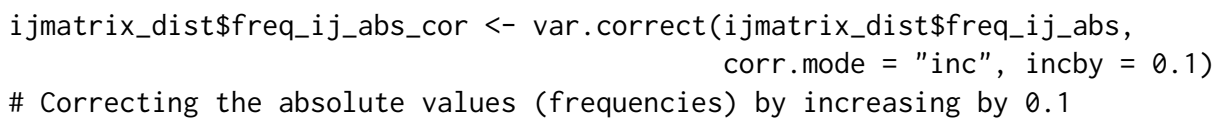

A fit of distance decay functions can be done with the package function huff.decay() which compares four types of possible distance decay functions (linear, power, exponential, logistic). For both locations, "POS1" and "POS2", we test the influence of distance in km (d_km) and travel time in minutes (d_time) on the dependent variable (visitper1000):

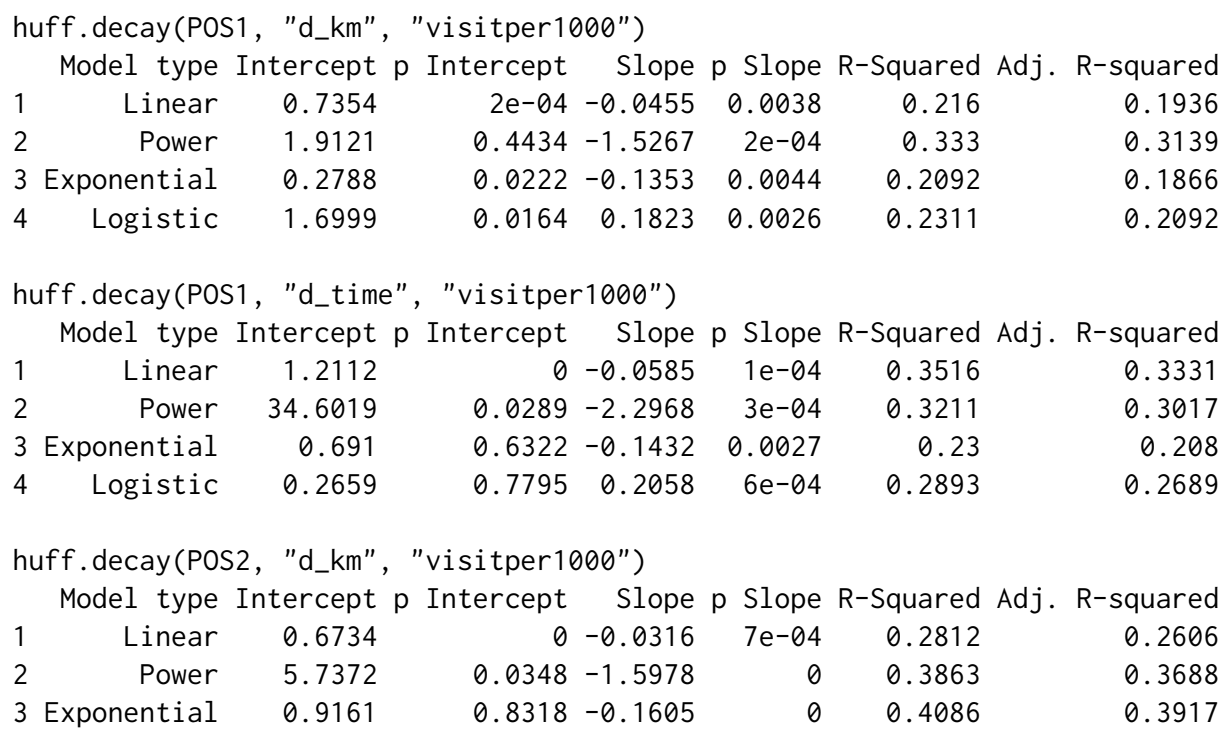


4

huff.decay (POS2, "d_time", "visitper1000")

Model type Intercept $\mathrm{p}$ Intercept Slope $\mathrm{p}$ Slope R-Squared Adj. R-squared

1 Linear 0.9353

2 Power 213.9932

$0-0.0411$

$1 \mathrm{e}-04$

0.3706

$7 e-04-2.7363$

0

0.4213

0.3526

Exponential

2. 3946

$0.14-0.184$

0.4191

0.4048

Logistic $\quad-1.8572$

$0.031 \quad 0.2441$

0.3835

0.4025

0.3659

The huff.decay () function returns a "data.frame" containing a summary of the regression results and a plot of the four estimated functions and the observed values (see Figure 1). The output shows the model estimators (Intercept and Slope), their p-values ( $p$ Intercept, $p$ Slope) and the goodness of fit measures (R-Squared, Adj. R-Squared) for every model type.
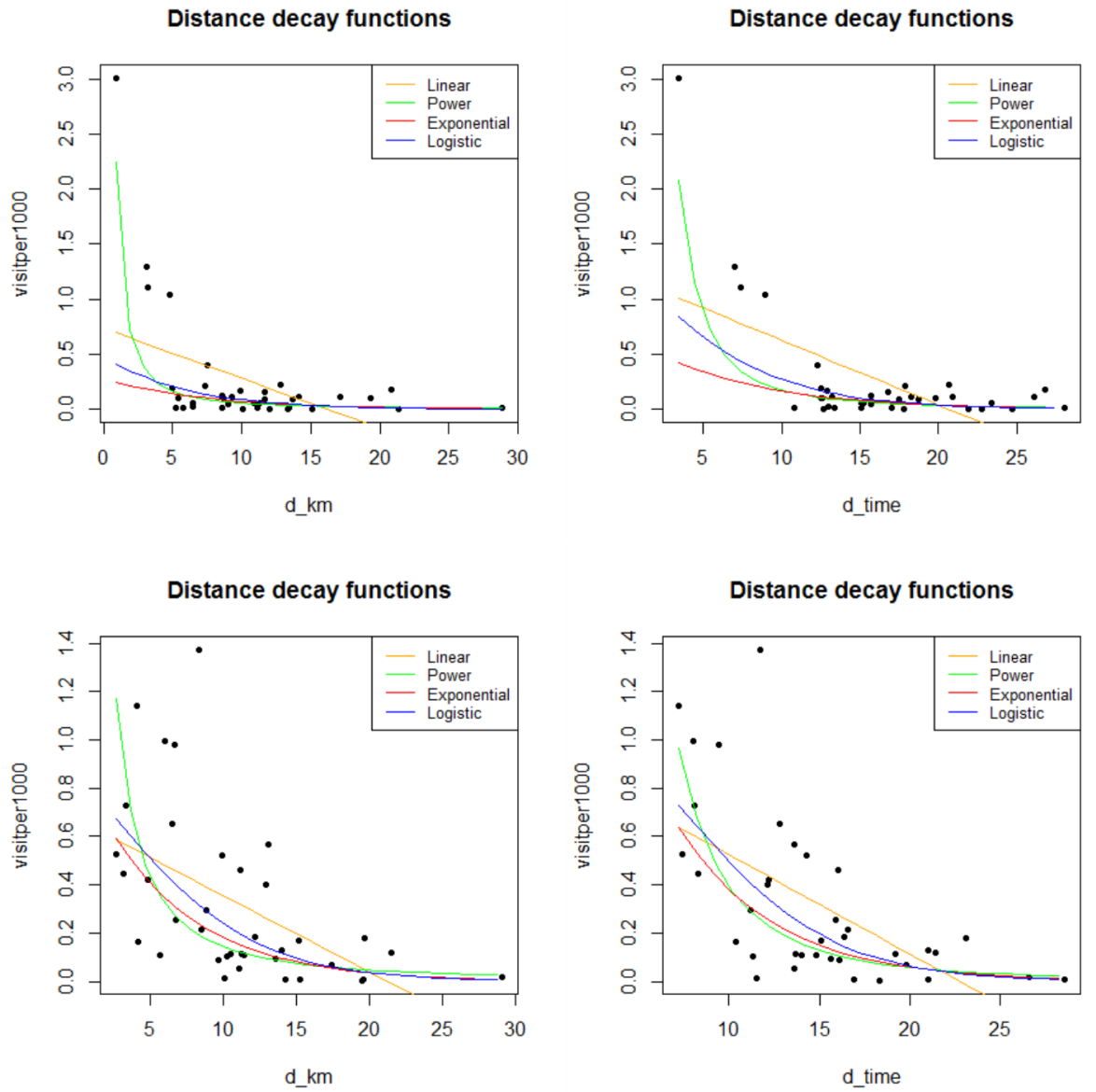

Figure 1: Distance decay functions for POS1 (top) and POS2 (bottom).

Note that the nonlinear models are not fitted via nonlinear regression but by linearization and retransformation, thereafter, since the usually used distance decay functions mentioned above are intrinsically linear (Rawlings et al., 1998). Internally, the linearized models are fitted via $1 \mathrm{~m}($ ). It is important to say that the usage of logarithmic transformations has, apart from many advantages of linearization, also serious drawbacks: with respect to gravity models, Silva and Tenreyro (2006) point out that OLS fitting of log-transformed data produces significant biases depending on heteroscedasticity. The same issue is also addressed by Manning and Mullahy (2001).

Huff (1962) assumed that a power function fits best to describe the distance decay. Since other types of distance decay functions are possible, Kanhäußer (2007) uses the explained variance as a criterion for choosing the best function type. Note that, strictly speaking, the $R^{2}$ values of the models can not be compared directly since they rest on different dependent variables. In the practical application, the choice for the preferred function type should be based on examining the model results and the plot as a case-by-case decision. With respect to $R^{2}$ the best distance decay functions for the two locations are:

$$
\hat{I}_{i j_{\text {POS1 }}}=1.91 d_{-} k m_{i j}^{-1.53},
$$




$$
\begin{gathered}
\hat{I}_{i j_{P O S 1}}=1.21-0.06 d_{-} \text {time }_{i j}, \\
\hat{I}_{i j_{\text {POS } 2}}=0.92 e^{-0.16 d_{-} k m_{i j},} \\
\hat{I}_{i j_{\text {POS } 2}}=213.99 d_{-} t i m e_{i j}^{-2.74},
\end{gathered}
$$

where $\hat{I}_{i j_{\text {POS } 1}}$ and $\hat{I}_{i j_{\text {POS }}}$ is the expected value of interaction intensity from $i$ to $j$ (visitors per 1,000 inhabitants) for the supply locations POS1 and POS2, respectively, $d_{-} k m_{i j}$ is the distance from $i$ to $j$ in $\mathrm{km}, d_{-}$time $_{i j}$ is the travel time from $i$ to $j$ and $e$ is Euler's number $\approx 2.71828$.

As expected, the distance/travel time influences the interaction intensity significantly and, as Huff (1962) states, mostly exponentially. In the second case, the regression regarding POS1 with the travel time, surprisingly, the best fit can be achieved by a linear function. But, all in all, the model fits can be regarded as rather poor, since the highest $R^{2}$ is equal to 0.42 in the fourth function (POS2 with travel time). Of course, that is because the distance/travel time is just one important determinant of store choice, while the attraction and other attributes of the retail locations are not considered here.

\section{Econometric market area analysis using the MCI Model}

Since, in the Huff Model, the store choices are explained by sales area and travel time, we want to test these hypotheses empirically with respect to grocery shopping trips. First, we have to calculate the dependent variable (market shares) and to link it to the explanatory variables in an interaction matrix, then we need to apply the log-centering transformation and, finally, we have to fit the MCI Model.

As in the former example, we use the shopping1 dataset which also contains questions about the general shopping behaviour. The respondents were asked about the destination of their last grocery shopping trip (gro_purchase_code) and the related expenditures (gro_purchase_expen).

We have to clean our working dataset from respondents living outside our study area, since we want to analyze the shopping patterns of the grocery shoppers in the eastern districts of Karlsruhe:

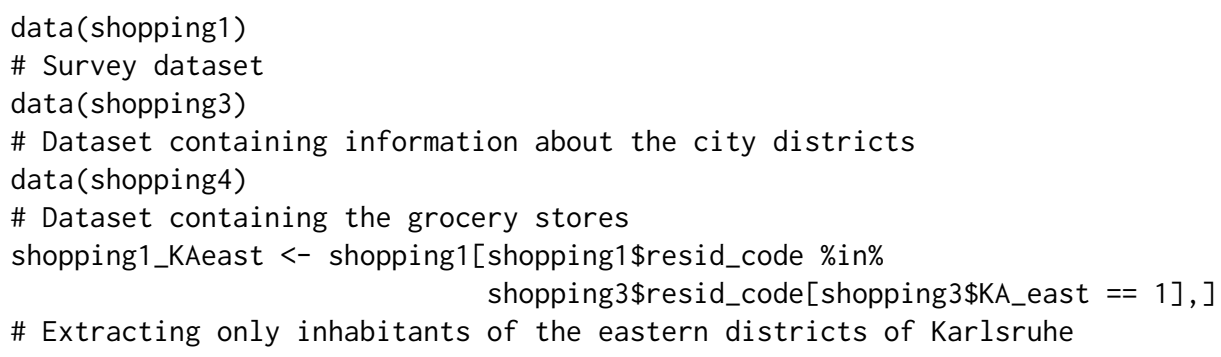

From the adjusted dataset, we create an interaction matrix using the function i jmatrix.create() with default values (no further adjusting except ignoring NA values). The calculation includes the shopping trip frequency that is counted automatically and the expenditures that must be specified separately by stating the variable containing the individual trip expenditures, gro_purchase_expen. The interaction matrix is stored in a new "data. frame", i jmatrix.

ijmatrix <- ijmatrix.create(shopping1_KAeast, "resid_code", "gro_purchase_code", "gro_purchase_expen")

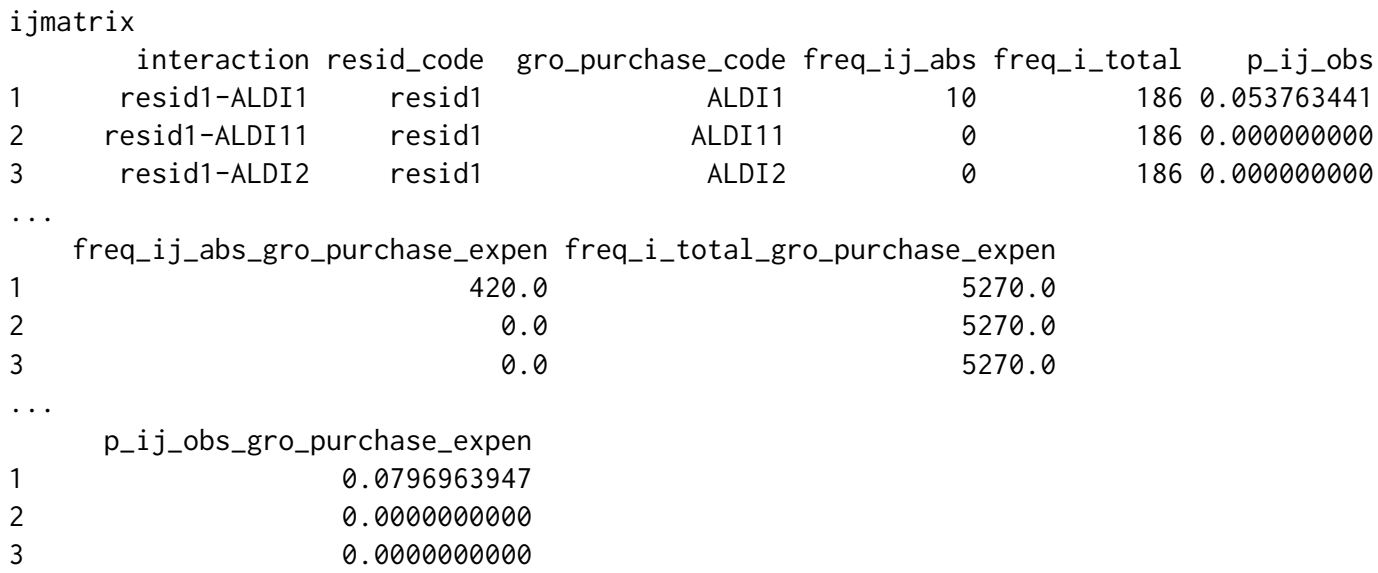


suppliers (121 rows). Structured as mentioned above, there are no zero values anymore and the absolute values (freq_ij_abs and freq_ij_abs_POS_expen) are increased by 0.1 :

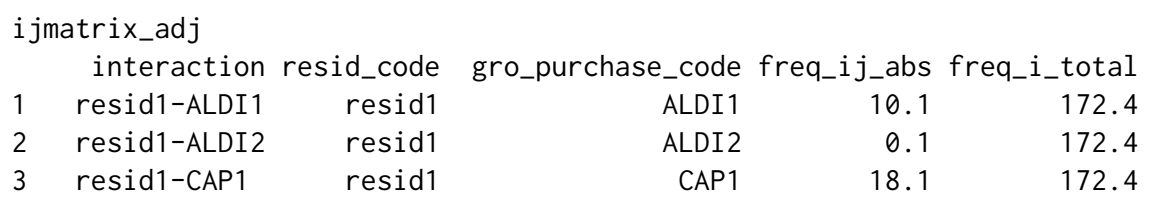

p_ij_obs freq_ij_abs_gro_purchase_expen freq_i_total_gro_purchase_expen

$10.0585846868 \quad 420.1 \quad 4745.4$

$20.0005800464 \quad 0.1 \quad 4745.4$

$3 \quad 0.1049883991 \quad 224.1 \quad 4745.4$

$\ldots$

p_ij_obs_gro_purchase_expen

$8.852784 \mathrm{e}-02$

$2.107304 \mathrm{e}-05$

$4.722468 \mathrm{e}-02$

In the next step, we have to add the travel times stored in the dataset shopping2 (the route calculation was made in $\mathrm{R}$ using the ggmap package) and the grocery store characteristics (sales area in sqm and store chain, collected in June 2016 subsequent to the survey) from the shopping 4 dataset:

ijmatrix_dist <- merge (ijmatrix_adj, shopping2, by.x="interaction", by.y="route")

\# Include the distances and travel times (shopping2)

ijmatrix_alldata <- merge (ijmatrix_dist, shopping4, by.x = "gro_purchase_code", by.y = "location_code")

\# Adding the store information (shopping4)

The next step is to apply the necessary log-centering transformation to the interaction matrix. The function mci. transmat () processes this transformation with a given number of MCI variables. The functions output is a "data. frame" containing the transformed variables (ready for OLS regression):

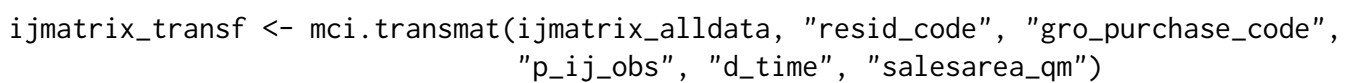

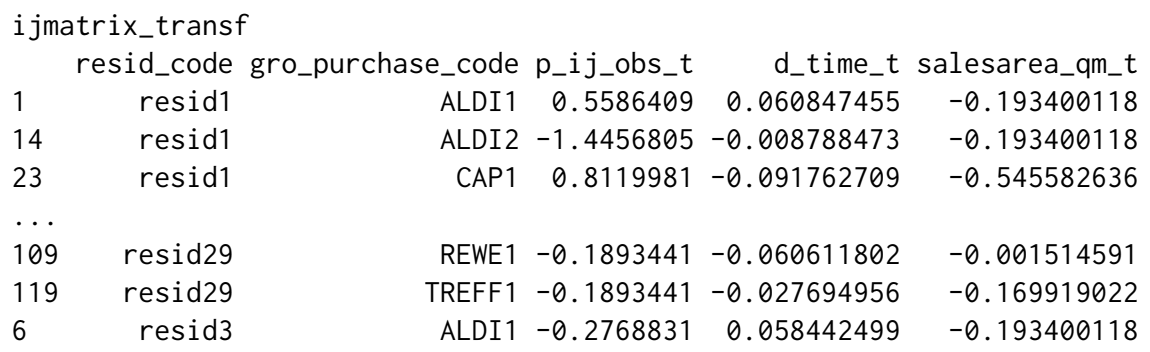

$\cdots$

In the transformed interaction matrix ( $2 \times 3$ rows are displayed), the column names of the origins (resid_code) and destinations (gro_purchase_code) are adopted from the columns in the input dataset. The metric $M C I$ variables are marked with a "_t $t$ " to indicate that they were transformed (e.g. $d_{-} t i m e \_t$ is the log-centering transformation of d_time which contains the travel time, $d_{i j}$ ). The transformed interaction matrix is in alphabetical order with respect to the origins (first) and the locations (second). If stated, the function recognizes dummy variables which are, of course, not transformed.

To combine transformation and fitting in one step, we use the function mci.fit() whose parameters are equal to those in mci. transmat () except that the column containing the market shares must be stated as the first variable. The default is a no-intercept model (to be set by the logical argument origin with default TRUE). The function returns an object of type " $1 \mathrm{~m}$ " which can be accessed via summary ():

mci_trips <- mci.fit(ijmatrix_alldata, "resid_code", "gro_purchase_code", "p_ij_obs", "d_time", "salesarea_qm")

\# shares: "p_ij_obs", explanatory variables: "d_time", "salesarea_qm"

summary (mci_trips) 


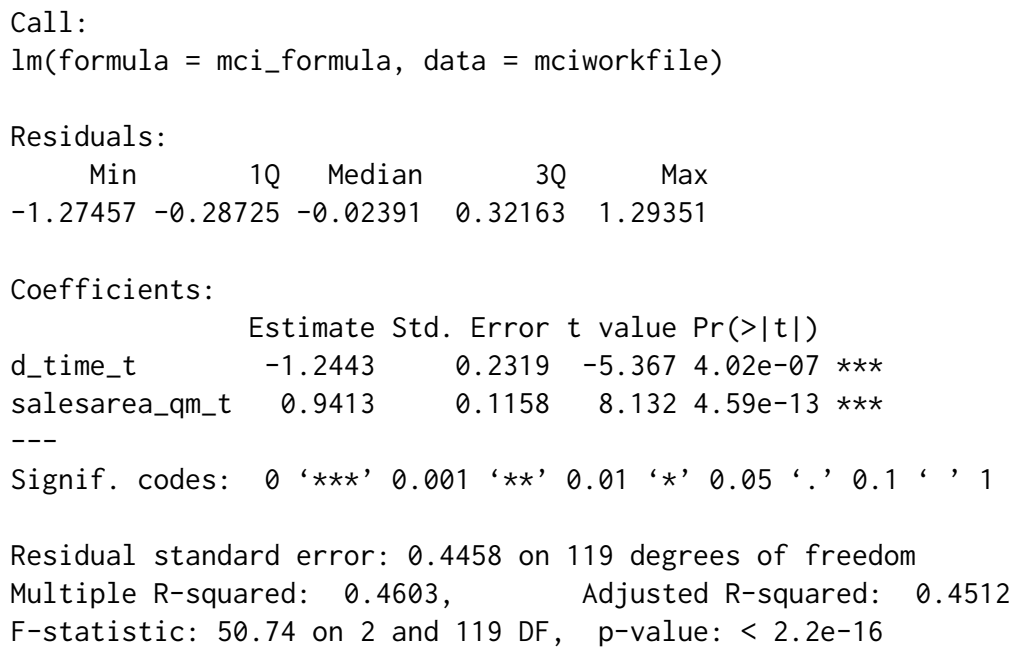

The output can be interpreted like any other linear model fitted by $\operatorname{lm}()$. The results show a strong significant influence of the explanatory variables (travel time and sales area) on the observed local market shares (both $p<0.001$ ). As the estimators are exponents in the original nonlinear model, the impact of travel time can be regarded as negative superlinear $(\lambda=-1.2443)$ while the effect of the sales area is positive sublinear $(\gamma=0.9413)$. Thus, the model fit corresponds to the theoretical underpinning of the utility function in the Huff Model (Huff, 1962).

For the interpretation of the explained variance it is noteworthy that the common formulation of $R^{2}$ is only designed for models that include an intercept. For no-intercept models, in $\mathrm{R}$, the function summary () returns a modified $R^{2}$ which reflects the explained variance of the no-intercept model but can not be compared to the related fit measure in a model including an intercept. Apart from this, the model fit seems to be in need of improvement $\left(R^{2}=0.4458\right.$ and $A d j \cdot R^{2}=0.4512$, respectively).

But the market shares with respect to customer flows are not to be confused with market shares of expenditures: especially in grocery shopping, there are different kinds of shopping trips, such as less frequent major trips with high efforts and expenditures and more frequent and fast fill-in trips with low expenditures (Reutterer and Teller, 2009). Thus, the MCI analysis is repeated with the shares of expenditures (p_ij_obs_gro_purchase_expen) as dependent variable:

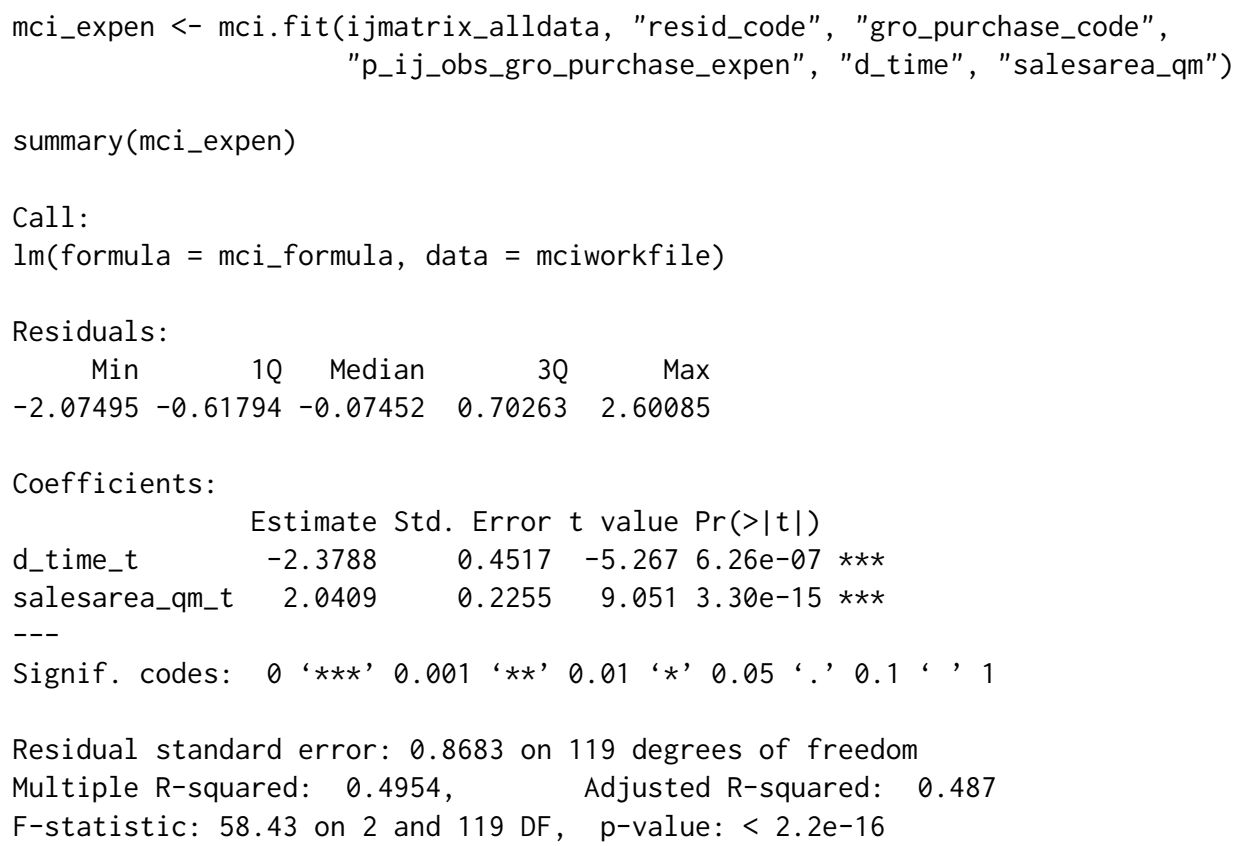

As in the first model, both predictors are highly significant, but, in contrast, the impact of size (sales area) is also superlinear. The model fit is a little better than in the first model, what may also be explained by a smaller bias based on the variable correction above: due to their dimensions, the increase of the absolute values by 0.1 has a smaller impact on the expenditures than on the shopping trips. 
The utility/attraction function (or, more precisely, its deterministic component) with respect to the shopping trips (first model) can be written as:

$$
U_{i j_{\text {trips }}}=\text { salesarea_qm } m^{0.9413} d_{-} \text {time }_{i j}^{-1.2443},
$$

where $U_{i j_{\text {trips }}}$ is the utility/attraction of grocery store $j$ for the customers in submarket/origin $i$, derived from the shares of empirically obtained shopping trips, salesarea_qm $m_{j}$ is the sales area of store $j$ and $d_{-}$time $_{i j}$ is the travel time from $i$ to $j$.

In consequence, the utility function is included in the Huff/MCI probability function. Thus, the local market shares of shopping trips can be estimated by:

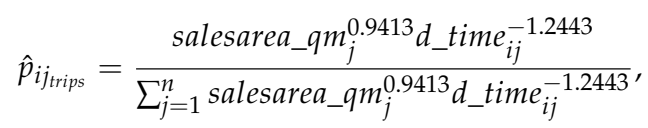

where $\hat{p}_{i j_{\text {trips }}}$ is the expected market share of shopping trips of the grocery store $j$ in the submarket $i$.

Analogously, the utility/attraction function and the market share/probability function of the expenditures (second model) are:

$$
\begin{gathered}
U_{i j_{\text {expen }}}=\text { salesarea_qm } m_{j}^{2.0409} d_{-} t i m e_{i j}^{-2.3788,} \\
\hat{p}_{i j_{\text {expen }}}=\frac{\text { salesarea_qm }{ }_{j}^{2.0409} d_{-} t i m e_{i j}^{-2.3788}}{\sum_{j=1}^{n} \text { salesarea_qm } m_{j}^{2.0409} d_{-} t i m e_{i j}^{-2.3788}},
\end{gathered}
$$

where $\hat{p}_{i j_{\text {expen }}}$ is the expected market share of expenditures of the grocery store $j$ in the submarket $i$.

A market share prediction can be done using the functions mci.shares() and huff.shares(). These functions can be used similarly but differ in the formulation of the utility/attraction function: according to the Huff Model, huff. shares() allows only two explanatory variables (attraction/size and transport costs) but three types of weighting function for each variable (power, exponential, logistic). The function mci. shares () is able to process any number of variables but only using the power function from the MCI Model either retransformed or transformed (inverse log-centering transformation).

We predict market shares using the function mci.shares() and the estimations from the second model (expenditures). The variables and their weightings are function arguments which have to be stated one after another (variable1, weighting1, variable2, weighting2, ...). The estimated interaction matrix containing the predicted shares is stored in a new dataset, expen:

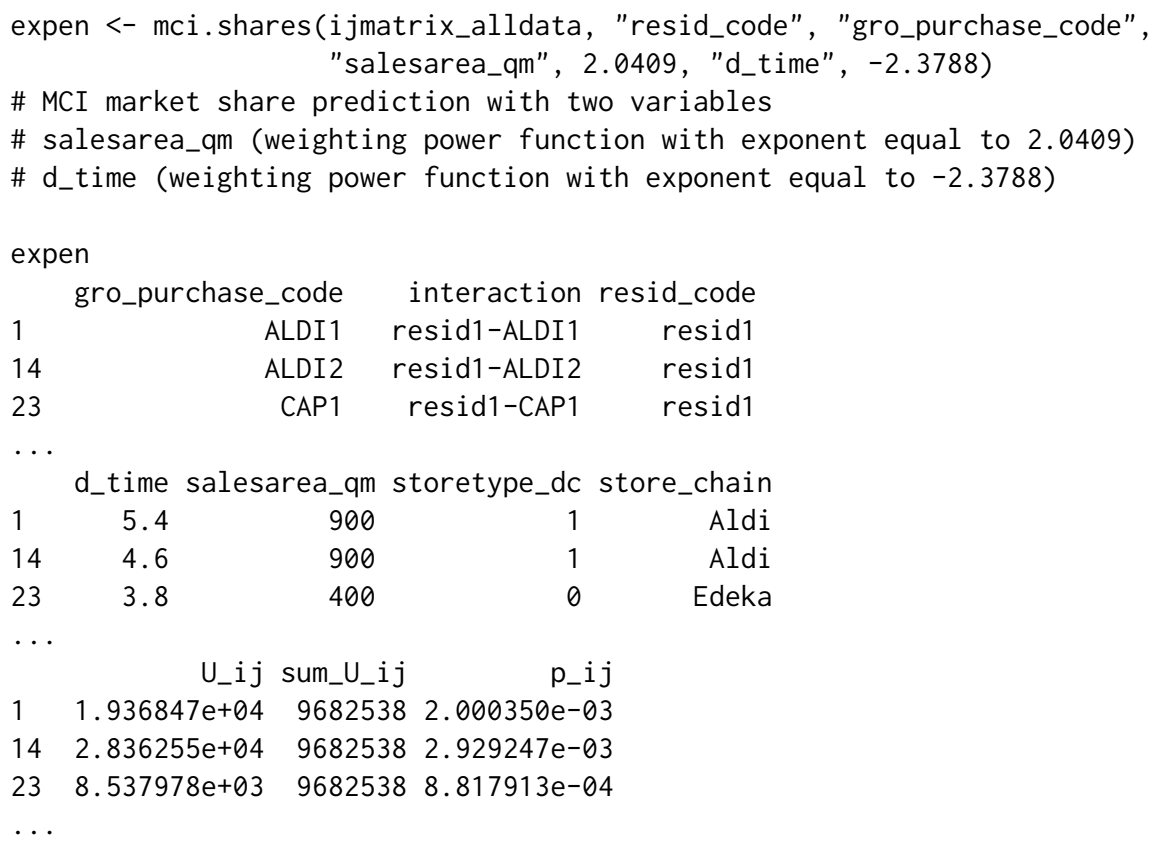

The interaction matrix (rows 1-3 are displayed) contains the submarkets (resid_code), the suppliers (gro_purchase_code), the interaction between them (interaction), the explanatory variables (d_time, salesarea_qm) and the steps of calculation, named according to the Huff Model (U_ij, sum_U_ij) and resulting in the local market shares stored in the last column ( $\left.p_{-} i j\right)$. The sum of $p_{-} i j$ is equal to the 
sum of submarkets, since, on the submarket level, the local market shares sum up to one.

Before using the MCI Model for further market share predictions, the validity of the model should be improved since store choices are, of course, not only influenced by size and transport costs. Especially in grocery retailing, there is a great heterogeneity between the store formats (supermarket, discounter etc.) and the store chains, such as concerning the image or price level of a chain. These more qualitative differences should be reflected in a grocery store market area model. According to Wieland (2015a), the model above is extended with dummy variables reflecting the grocery store chain.

The chains are already stored in the interaction matrix (column store_chain, adopted from shopping4). As they are nominal scaled variables in character format, they have to be converted to dummy variables using the function var. asdummy () which returns a new "data. frame" containing corresponding dummy variables $(0,1)$ named automatically based on the original characteristics and marked with "_DUMMY". Since they are in the same order, they can be directly attached:

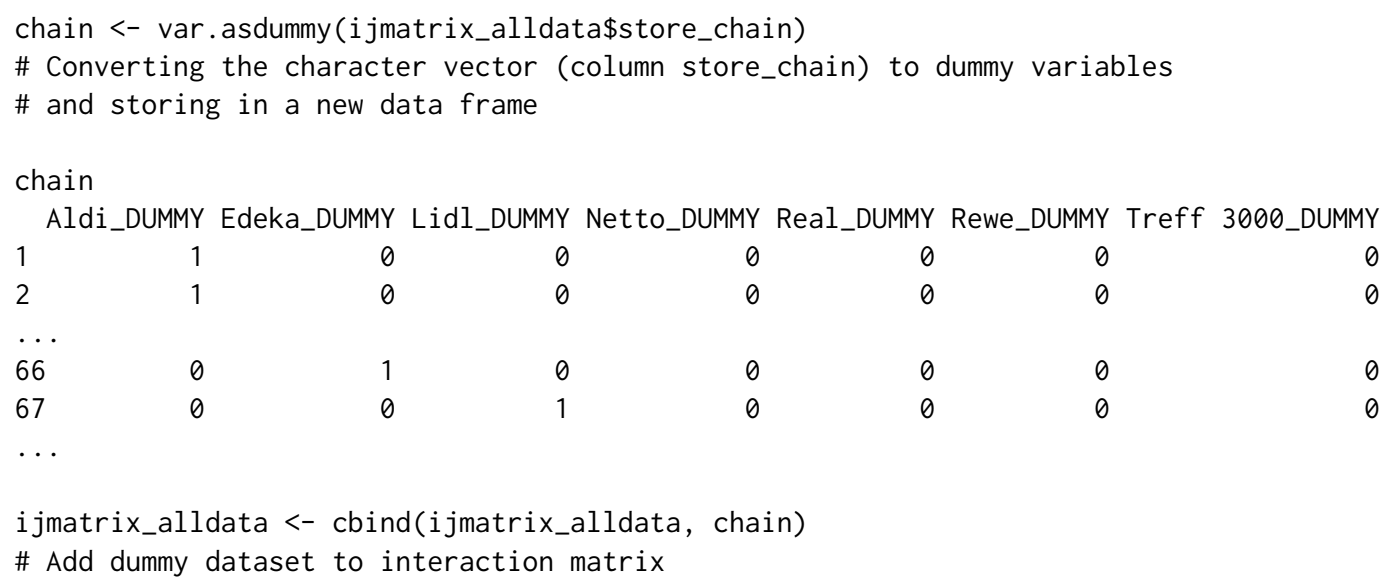

In the next step, we repeat the fitting of the second MCI Model (expenditures) including the new dummy variables. Since one dummy is explained by the content of all the others, the last dummy is not used:

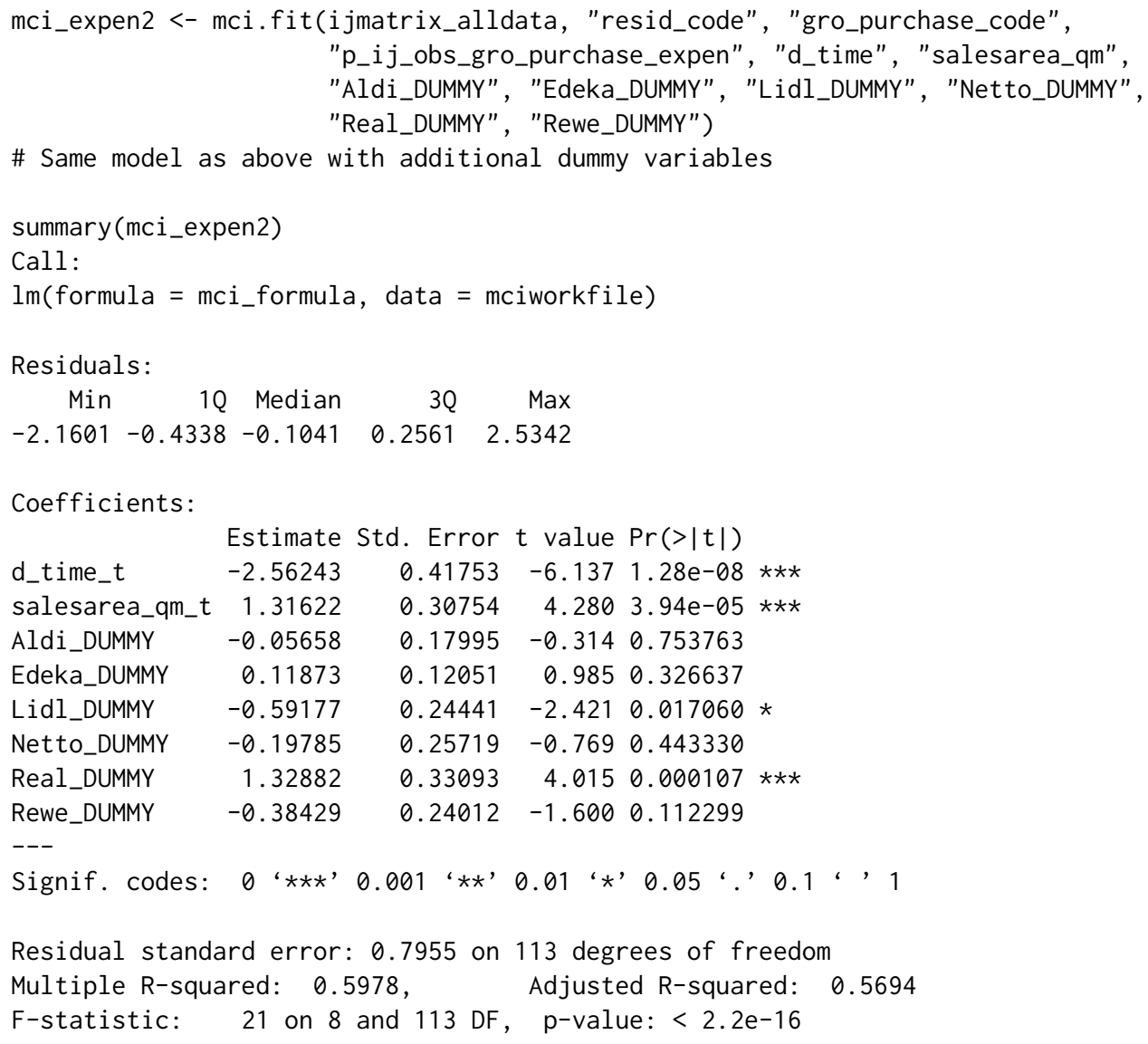

The independent variables d_time_t and salesarea_qm_t are still statistically significant (both 
$p<0.001)$ but especially the latter estimator has strikingly decreased. Two dummy variables are also significant: Lidl_DUMMY $(p<0.05)$ and Real_DUMMY $(p<0.001)$. Regarding $R^{2}$ and Adj. $R^{2}$, the model validity could be improved compared to the former model.

As this new model includes dummies, it would not make any sense to insert the estimated parameters in the multiplicative MCI function: if one dummy variable is equal to zero, the complete term is equal to zero. Thus, in this case, it is necessary to use the inverse log-centering transformation which leads to the following transformed utility/attraction function:

$$
\begin{aligned}
& \hat{y}_{i j_{\text {expen }}}=-2.56243 \log \left(\frac{d_{-} \text {time_t }}{{ }_{\text {itime_t }}}\right)+1.31622 \log \left(\frac{\text { salesarea_qm_t }}{d_{j}}\right) \\
& -0.59177 L i d l \_D U M M Y_{j}+1.32882 R e a l \_D U M M Y_{j} \text {, }
\end{aligned}
$$

where $\hat{y}_{i j_{\text {expen }}}$ is the log-centering transformed utility/attraction of store $j$ for the customers in $i$, $\widetilde{d_{-} \text {time_}} t_{i}$ and salesarea_qm_t$t_{j}$ are the geometric means of $d_{-}$time $t_{i j}$ and salesarea_qm_t$t_{j}$, respectively, and Lidl_DUMMY $Y_{j}$ and Real_DUMMY $Y_{j}$ are dummy variables reflecting if the store chain of $j$ is Lidl or Real, respectively. Now, the local market shares are defined by:

$$
\hat{p}_{i j_{\text {expen }}}=\frac{e^{\hat{y}_{i j \text { expen }}}}{\sum_{j=1}^{n} e^{\hat{y}_{i j \text { expen }}}},
$$

where $\hat{p}_{i j_{\text {expen }}}$ is the expected market share of store $j$ in $i$ and $e$ is Euler's number $\approx 2.71828$.

We repeat the market shares prediction including the dummies and their weights. The inverse log-centering transformation, which is required here, can be used in the function mci.shares() by stating the function parameter mcitrans to "ilc" (default: "lc"). In the next step, the total expenditures for each grocery store and the corresponding over-all shares are computed by the function shares. total():

expen2 <- mci.shares(ijmatrix_alldata, "resid_code", "gro_purchase_code",

"salesarea_qm", 1.31622, "d_time", -2.56243, "Lidl_DUMMY", -0.59177,

"Real_DUMMY", 1.32882, mcitrans = "ilc")

\# MCI market share prediction with four variables

\# (ratio-scaled variables are log-centering transformed)

\# salesarea_qm (multiplicative weighting with factor equal to 1.31622 )

\# d_time (multiplicative weighting with factor equal to -2.56243 )

\# Lidl_DUMMY (multiplicative weighting with factor equal to -0.59177 )

\# Real_DUMMY (multiplicative weighting with factor equal to 1.32882 )

shares.total(expen2, "resid_code", "gro_purchase_code", "p_ij", "freq_ij_abs_gro_purchase_expen")

\# Expected total sales and shares based on the observed local

\# market potential (sum of all obtained expenditures for each origin)

$\begin{array}{lrrr} & \text { suppliers_single } & \text { sum_E_j } & \text { share_j } \\ 1 & \text { ALDI1 } & 16.029089 & 0.008058517 \\ 2 & \text { ALDI2 } & 2.157771 & 0.001084805 \\ 3 & \text { CAP1 } & 7.101650 & 0.003570307 \\ 4 & \text { EDEKA1 } & 790.385662 & 0.397361072 \\ 5 & \text { EDEKA2 } & 34.432270 & 0.017310592 \\ 6 & \text { EDEKA3 } & 25.098495 & 0.012618099 \\ 7 & \text { LIDL1 } & 40.925354 & 0.020574946 \\ 8 & \text { NETT01 } & 2.063759 & 0.001037541 \\ 9 & \text { REAL1 } & 1019.935563 & 0.512765741 \\ 10 & \text { REWE1 } & 35.451053 & 0.017822778 \\ 11 & \text { TREFF1 } & 15.506130 & 0.007795602\end{array}$

The result of shares.total is a "data.frame" containing the suppliers (suppliers_single), the total values (sum_E_ $j$ ) and the corresponding over-all market shares share $e_{-}$, where the sum of all share ${ }_{-} j$ is equal to one. Here, the stores with the biggest shares of customer expenditures are "REAL 1 " $(51.28 \%)$ and "EDEKA1" (39.74\%).

Now, we analyze the impact of a change in the competitive environment: the biggest grocery store in the study area is Real (gro_purchase_code = "REAL1"). On condition that the sales area of this store is increased by $10 \%$ (because of an increase of offered goods), how will, ceteris paribus, the 
purchasing power flows with respect to this supplier and to all other stores change? First, we update the regarded variable in the existing interaction matrix:

ijmatrix_alldata[ijmatrix_alldata\$gro_purchase_code == "REAL1", ]\$salesarea_qm <- 8525
\# Replacing the sales area of REAL1 with a new value: 8525 sqm (increase of $10 \%$ )

Now, we only have to repeat the MCI market share prediction above:

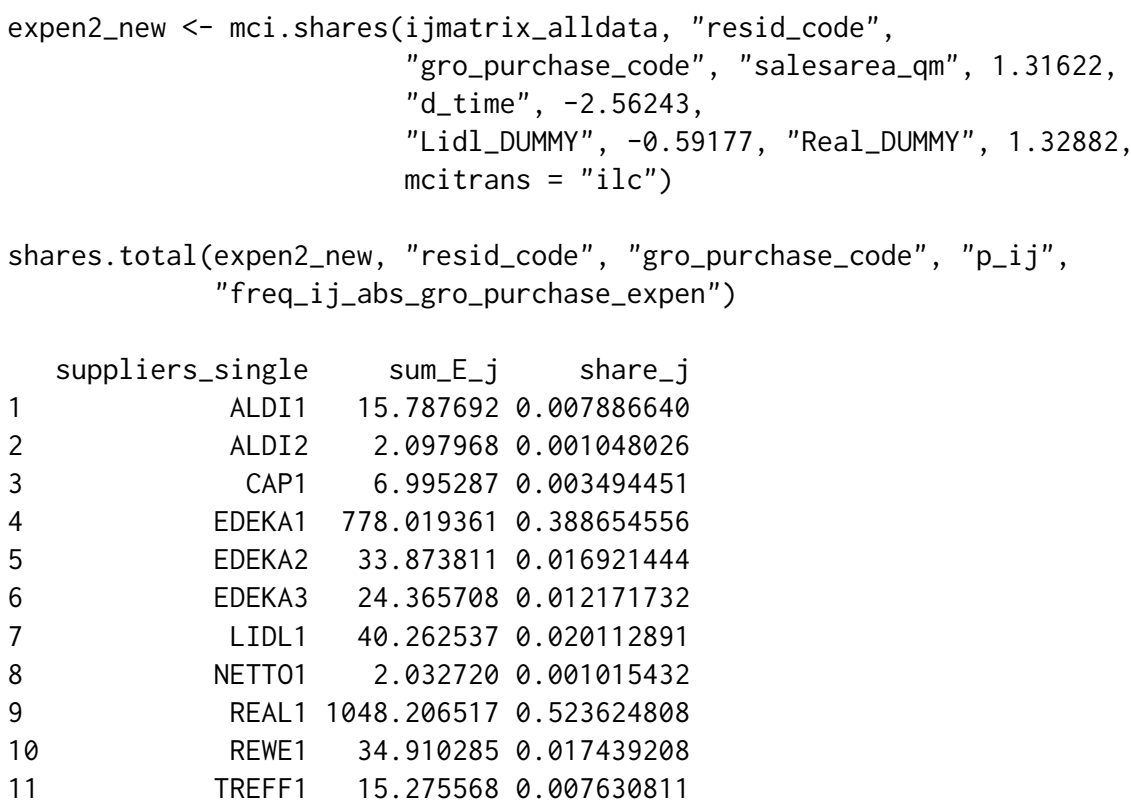

The results in the total sales/shares table show an impact of the trading-up in the regarded hypermarket: the over-all share of Real increases from $51.28 \%$ to $52.36 \%$. The other stores are affected differently: the over-all share of EDEKA1 decreases from $39.74 \%$ to $38.87 \%$. Since this model does not consider any kind of agglomeration economies, the market shares of the competitors decrease dependent on their proximity to the hypermarket and the spatial distribution of customers.

It should be noticed that the survey in the shopping1 dataset is not statistically representative, since it is a POS survey not regarding customers shopping at other supply locations. Thus, the analyses and results shown here should not be overinterpreted but regarded as an example how to use the MCI-related functions in the MCI package.

\section{Huff Model optimization}

The final example deals with the problem of fitting the Huff Model on condition that no empirically observed store choices, market shares and market areas, respectively, are available. The aim of the analysis is to estimate the market areas of the grocery stores in Freiburg, Germany, based on their total annual sales and their "attraction" (size).

The dataset Freiburg1 contains the preliminary stage of a Huff interaction matrix, containing the origins (statistical districts of Freiburg, column district), codes representing the grocery stores (store), the sales area of these stores in sqm (salesarea) and the street distances between the origins and the stores (distance). The grocery stores and their characteristics were obtained in spring 2015 (Wieland, 2015b), while the street distances were calculated via network analysis in GRASS (GRASS Development Team, 2015) using OpenStreetMap vector data.

data(Freiburg1)

\# Distance matrix and sales area

First, we try to approximate the market areas using a conventional Huff Model calculation using the function huff. shares(). This function is similar to the mci.shares() function and allows two explanatory variables (size, transport costs) which can be weighted by given parameters in a power, exponential or logistic function. The function type (power) and the exponents are set corresponding to the default parameters of the Huff Model: $\gamma=1$ and $\lambda=-2$ (Güssefeldt, 2002):

huff_mat <- huff.shares (Freiburg1, "district", "store", "salesarea", "distance")

\# Market area estimation using the Huff Model with standard parameters

\# $($ gamma $=1$, lambda $=-2)$ 
In the next step, the total annual sales of the grocery stores are computed based on the estimated interaction probabilities/local market shares and the grocery purchasing power potential on the district level in EUR (calculated based on the local population size and the national average expenditures for groceries), stored in the dataset Freiburg2:

data(Freiburg2)

\# Grocery purchasing power on the city district level

huff_mat_pp <- merge (huff_mat, Freiburg2)

\# Adding the purchasing power data for the city districts

huff_total <- shares.total (huff_mat_pp, "district", "store", "p_ij", "ppower")

\# Total expected sales and shares

huff_total

suppliers_single sum_E_j share_j

$1 \quad 1 \quad 4057591 \quad 0.010759819$

$2 \quad 10 \quad 5809861 \quad 0.015406444$

$3 \quad 11 \quad 1289847 \quad 0.003420383$

$4 \quad 12 \quad 7103210 \quad 0.018836115$

$5 \quad 13 \quad 3476313 \quad 0.009218400$

$\ldots$

The new dataset huff_total contains the expected total annual sales in EUR (sum_E_j) and the corresponding over-all market shares (share $\_j$ ). Since the "real" annual sales are known (calculated by chain-based average retail space productivity, stored in the dataset Freiburg3), we compare the expected values to the observed values using the help function model. fit():

data(Freiburg3)

\# Annual sales of the grocery stores

huff_total_control <- merge(huff_total, Freiburg3, by.x = "suppliers_single", by.y = "store")

model.fit(huff_total_control\$annualsales, huff_total_control\$sum_E_j, plotVal = TRUE)

\$resids_sq_sum

[1] $2.125162 \mathrm{e}+15$

\$pseudorsq

[1] 0.5128422

\$globerr

[1] 0.5210329

\$mape

[1] 0.6383766

The function model.fit() returns a "list" with four entries containing the following goodnessof-fit measures: the sum of the squared residuals (resids_sq_sum), a Pseudo- $R^{2}$ measure (pseudorsq), the global error (globerr) and the MAPE (mape), as described in the Huff Model section. Note that these fit measures are closely related to each other. Optionally, the function returns a plot to compare the observed and expected values graphically (see the plot in Figure 2, top left).

Obviously, the fit in this Huff Model market area estimation using the default values is quite poor as can be seen from the fit measures and, of course, from the plot. E.g. the sales of the most high-selling grocery store is extremely underestimated. From this, one can conclude that also the estimated market shares/market areas will not reflect the reality to some extent.

Thus, we have to use the optimization algorithm as discussed in the Huff Model section. The function huff. attrac() provides one iteration of this algorithm, requiring the interaction matrix, the local market potential and the total values (e.g. sales) of the suppliers. The tolerance value to accept a difference of individual total sales or not is set equal to 5, while the function output contains the estimated total values (Internally, huff. attrac() uses the function shares. total()). We apply the function to the three datasets (Freiburg1, Freiburg2 and Freiburg3):

huff_total_opt1 <- huff.attrac(Freiburg1, "district", "store", "salesarea", "distance", lambda $=-2$, dtype $=$ "pow", lambda2 $=$ NULL, 
Freiburg2, "district", "ppower",

Freiburg3, "store", "annualsales",

tolerance $=5$, output $=$ "total")

\# One-time optimization (one iteration) with an accepted difference of $+/-5 \%$

\# Output of total sales/shares

Note that this calculation includes a great many calculation steps while working with 63 stores and 42 statistical districts. In a test environment (computer with CPU: Intel Core i3-2100, RAM: 4.00 GB, OS: Windows 7 64bit), the command above takes about 43 seconds.

\begin{tabular}{rrrrrrr} 
huff_total_opt1 & & & & \\
\multicolumn{1}{c}{ suppliers_single } & sum_E_j & share_j & total_obs & diff & attrac_new_opt \\
1 & 1 & 7097226 & 0.018820246 & 7210720 & 113494.39 & 1329.26622 \\
2 & 10 & 5043058 & 0.013373057 & 5600000 & 556941.50 & 1400.00000 \\
3 & 11 & 1136322 & 0.003013270 & 1000000 & -136321.73 & 193.82148 \\
4 & 12 & 2849360 & 0.007555862 & 2776000 & -73360.04 & 271.22161
\end{tabular}

Since the option output was set to "total", the huff. attrac() function returns a "data.frame" (rows 1-4 are displayed) that contains a comparison between the observed (total_obs) and the expected total values (sum_E_j) as well as the corresponding difference (diff) and the estimated new attractions (attrac_new_opt). If output is set to "matrix", the function returns an interaction matrix equal to the output of mci. shares() or huff. shares().

Next, the validity analysis of the new model using model. fit() is repeated as described above:

model.fit(huff_total_opt1\$total_obs, huff_total_opt1\$sum_E_j, plotVal = TRUE)

\# total_obs = observed total values, originally from dataset Freiburg 3

\# sum_E_j = expected total values

\$resids_sq_sum

[1] $2.901841 \mathrm{e}+14$

\$pseudorsq

[1] 0.9334801

\$globerr

[1] 0.1564878

\$mape

[1] 0.1620126

The goodness-of-fit measures and the plot (see the plot in Figure 2, top right) reveal a much better fit: the Pseudo- $R^{2}$ increases from 0.51 to 0.93 while the error measures decrease accordingly.

To extend this optimization algorithm to a given number of iterations, the MCI package provides the function huff.fit(). First, we run two iterations decreasing the tolerance value equal to one which means a more strict check. Since this optimization takes some time, we enable the printing of status messages. The output of the function huff. fit() is equal to the output of huff. attrac() and can be processed in the same way. As above, the estimated total sales are compared to the observed sales using model. fit():

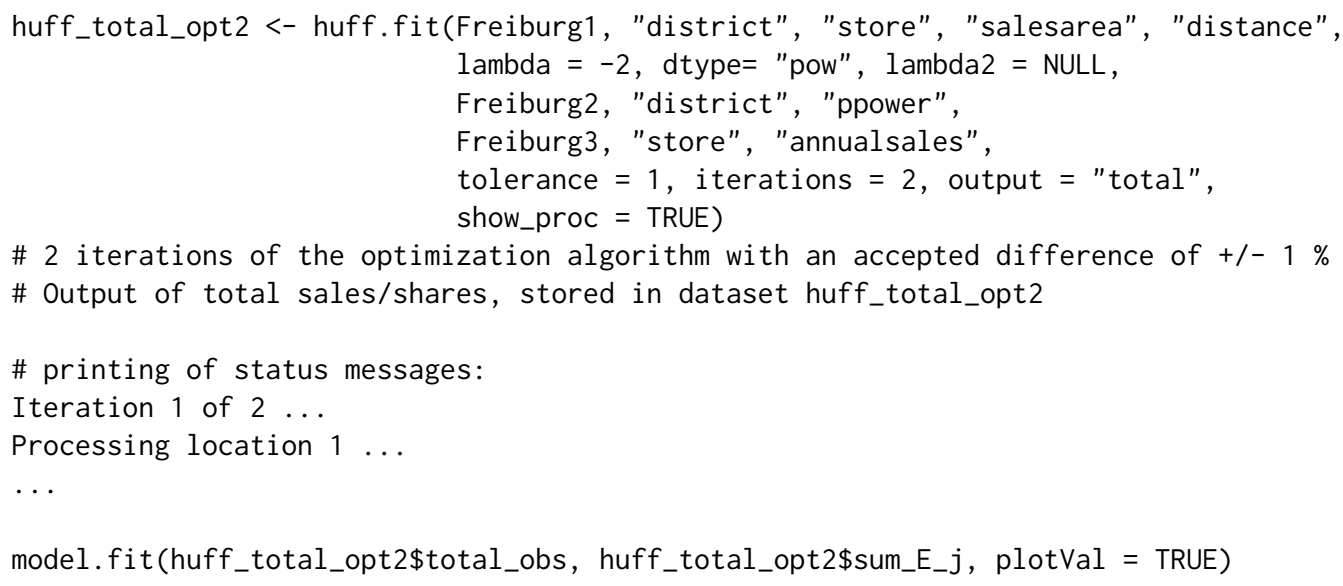


\# total_obs = observed total values, originally from dataset Freiburg3

\# sum_E_j = expected total values

\$resids_sq_sum

[1] $4.806282 \mathrm{e}+13$

$\$$ pseudorsq

[1] 0.9889824

$\$ g l o b e r r$

[1] 0.05946104

\$mape

[1] 0.0618133

To run the algorithm twice with a smaller tolerance leads to a much better fit: while Pseudo- $R^{2}$ increases from 0.93 to 0.98 , the global error and the MAPE reduce from about 15 and $16 \%$ to about $6 \%$, respectively. This improvement is also obvious when looking at the plot (Figure 2, bottom left).

In the test environment mentioned above, this huff. fit operation takes about one and a half minute ( 89 seconds). Consequently, to extend the procedure to more iterations means also an increase of calculating time. We repeat the algorithm with 10 iterations and compare the results once more:

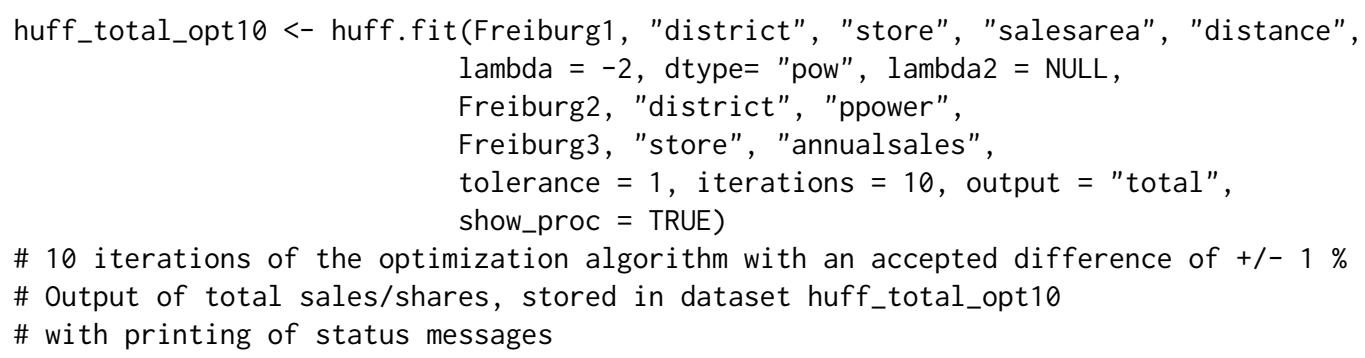

\$pseudorsq

[1] 0.9999574

\$globerr

[1] 0.004508996

\$mape

[1] 0.004405252

This operation is, of course, very time-consuming: in the test environment mentioned above, ten iterations of the algorithm took about five minutes (308 seconds), while the time of an iteration decreases since the local fits (for each store/locations) also gets better with each iteration. The final result is a nearly perfect fit with a MAPE of about $0.4 \%$ and a global error of about $0.5 \%$ while the Pseudo- $R^{2}$ approaches the maximum (0.99). The expected annual sales are highly accurate as can be seen in the corresponding plot (Figure 2, bottom right).

The function huff.fit() allows an evaluation of the iterations by returning the corresponding global fit measures for each step (Internally, huff. fit() uses the model. fit() function). We set the function parameter output $=$ "diag" to make the function return a "data.frame" containing the iteration statistics:

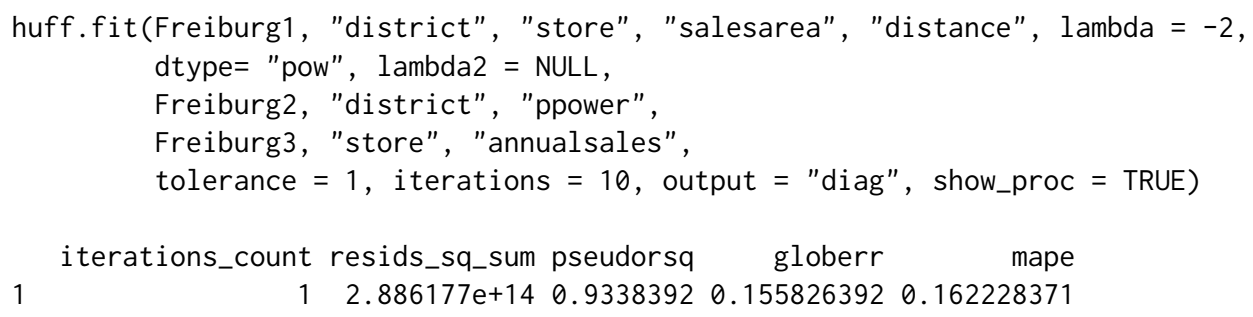




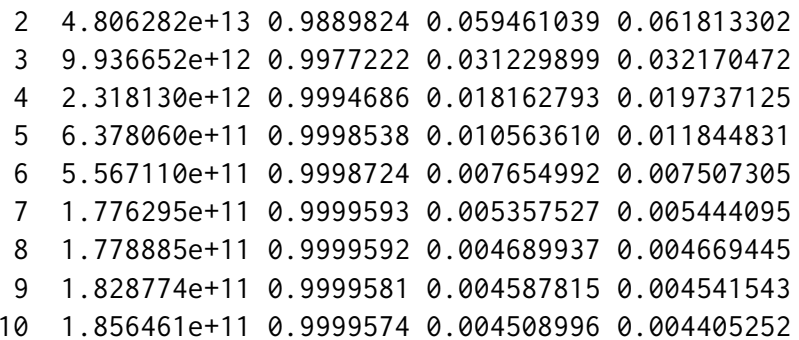

Obviously, all goodness-of-fit measures show an improvement of the model fit with each iteration. But there is no noticeable improvement after the eighth iteration. All in all, the accuracy of the results are determined by the error tolerance (parameter tolerance) and the number of iterations (parameter iterations) which are stated by the user who has to trade off accuracy against computing time.
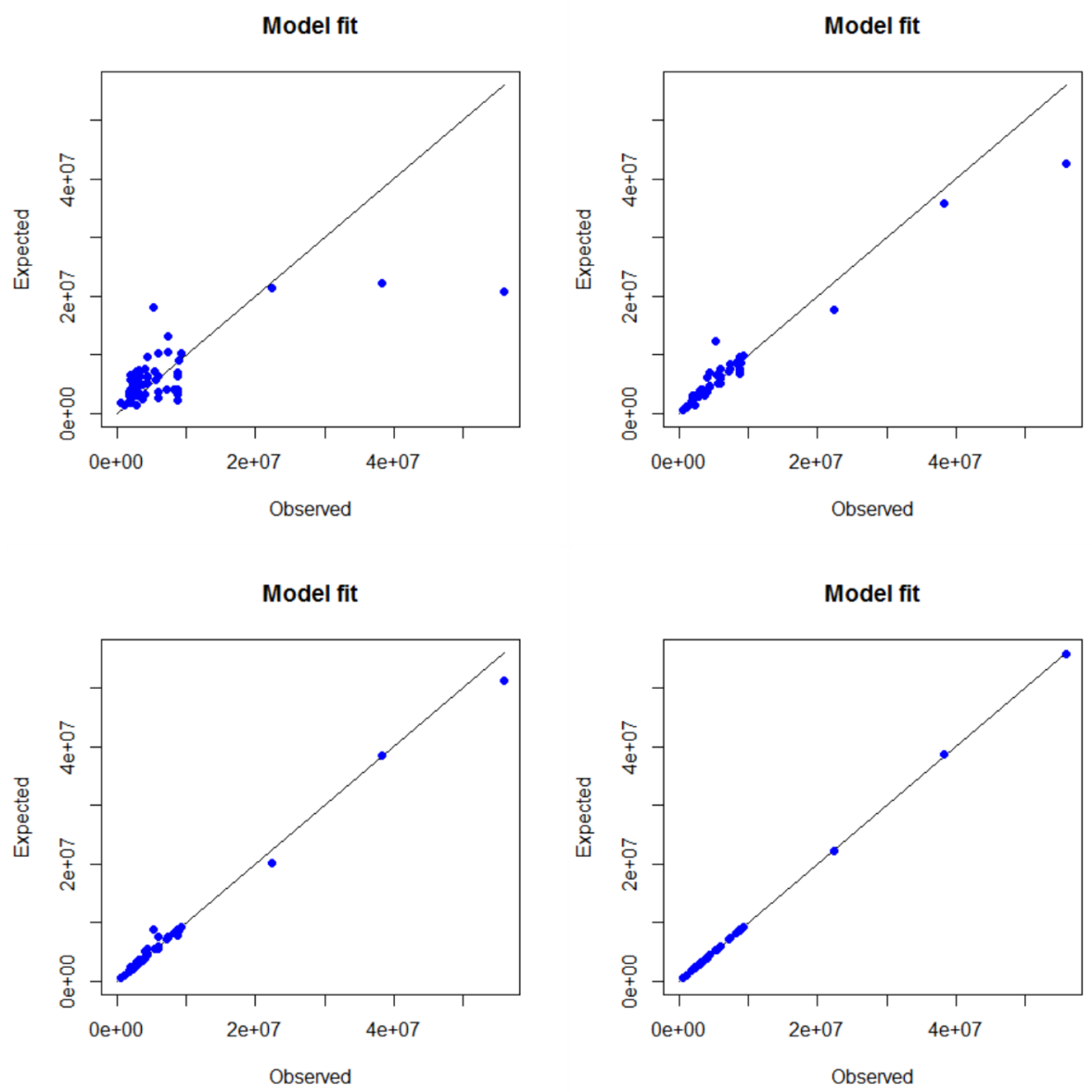

Figure 2: Huff Model fit algorithm.

\section{Conclusions and limitations}

Model-based market area analysis for retail and service locations includes 1) theoretical considerations, 2) collection of empirical data regarding the locations and the customers, 3) data processing and, in some cases, data transformation, 4) fitting of the used models and 5) the market area prediction itself. While the first two aspects can not be offered by a statistical software, the presented package MCI provides several functions to process the other mentioned steps by implementing the Huff Model and the Multiplicative Competitive Interaction (MCI) Model into R.

The focus of the package is 1) on model fitting via OLS regression (MCI Model) or iterative optimization (Huff Model) and 2) on data preparation, while both aspects are closely related (especially in the MCI Model). As a consequence, some other related substeps are not considered.

Though the package is designed to allow a data exchange with a GIS (e.g. ijmatrix.crosstab() to 
prepare an interaction matrix for a map visualization), it does not provide any GIS functions. Thus, the GIS-related steps of market area analysis have to be borrowed from other packages: especially distance or travel time calculations are needed what can be done using GIS-orientated packages like ggmap which utilizes the Google API for routing (and was used in the example dataset shopping2), osmar (Eugster and Schlesinger, 2013) and osrm (Giraud, 2016) providing similar functions with respect to OpenStreetMap, or the huff-tools package mentioned above.

In econometric market area analyses using the MCI Model, also further diagnostics of the model are recommended, especially with respect to the possible violations of the OLS-related assumptions, such as heteroscedasticity or multicollinearity. A discussion of specific problems and opportunities regarding logarithmic transformations can be found in Silva and Tenreyro (2006) and Manning and Mullahy (2001). The violation of OLS assumptions and possible solutions have beed addressed in MCI studies several times (Nakanishi and Cooper, 1974; Kubis and Hartmann, 2007; Tihi and Oruc, 2012; Wieland, 2015a), but there are no corresponding extensions implemented in MCI yet. Other packages may be helpful for this analyses: since the implemented functions return "data.frame" (mci.transmat ()) and "lm" objects (mci.fit()), respectively, this data can be processed e.g. in car (Fox and Weisberg, 2011) for further diagnostics.

Another remaining step not yet provided by the presented package is the combination of the MCI Model with the Geographically Weighted Regression (GWR) which has been already used to identify spatial nonstationarity in the estimated parameters (Suárez-Vega et al., 2015; Wieland, 2015a). The GWR is implemented in R by the package spgwr (Bivand and Yu, 2015).

\section{Acknowledgements}

The author would like to thank the two anonymous reviewers for providing useful feedback that helped to improve the paper.

\section{Bibliography}

S. Baecker-Neuchl and H. Wagenseil. Das Ganze sehen: Räumliche Analysen zur Ermittlung des Zusammenhangs zwischen Umsatz- und Nachfragepotenzial. In O. Gansser and B. Krol, editors, Markt- und Absatzprognosen. Modelle - Methoden - Anwendung, pages 263-281. Springer-Verlag, 2015. URL https://doi.org/10.1007/978-3-658-04492-3_14. [p300]

B. R. Berman and J. R. Evans. Retail Management: A Strategic Approach. Pearson, 12 edition, 2013. [p298]

R. Bivand and D. Yu. Spgwr: Geographically Weighted Regression, 2015. URL https: //CRAN. R-project. org/package=spgwr. R package version 0.6-28. [p321]

G. Cliquet. Retail Location Models. In G. Cliquet, editor, Geomarketing: Methods and Strategies in Spatial Marketing, pages 137-163. John Wiley \& Sons, 2013. URL https://doi .org/10.1002/ 9781118614020.ch6. [p302, 303]

P. D. Converse. New laws of retail gravitation. Journal of Marketing, 14(3):379-384, 1949. URL https://doi.org/10.2307/1248191. [p298]

L. G. Cooper and M. Nakanishi. Standardizing variables in multiplicative choice models. Journal of Consumer Research, 10(1):96-108, 1983. URL https://doi .org/10.1086/208948. [p304]

L. G. Cooper and M. Nakanishi. Market-Share Analysis: Evaluating Competitive Marketing Effectiveness. International series in quantitative marketing. First published in 1988 by Kluver, E-Book edition, 2010. URL http://www. anderson. ucla.edu/faculty/lee. cooper/MCI_Book/B00KI2010.pdf. [p301, 302]

M. De Beule, D. Van den Poel, and N. Van de Weghe. An extended Huff-model for robustly benchmarking and predicting retail network performance. Applied Geography, 46(1):80-89, 2014. URL https://doi.org/10.1016/j.apgeog. 2013.09.026. [p300,301]

M. J. A. Eugster and T. Schlesinger. Osmar: OpenStreetMap and R. R Journal, 5(1):53-63, 2013. URL https://journal.r-project.org/archive/2013-1/eugster-schlesinger.pdf. [p321]

J. Fox and S. Weisberg. An R Companion to Applied Regression. Sage, Thousand Oaks CA, 2nd edition, 2011. URL http://socserv. socsci.mcmaster.ca/jfox/Books/Companion. [p321]

T. Giraud. Osrm: Interface Between R and the OpenStreetMap-Based Routing Service OSRM, 2016. URL https://CRAN.R-project.org/package=osrm. R package version 3.0.0. [p321] 
T. Giraud and H. Commenges. SpatialPosition: Spatial Position Models, 2016. URL https://CRAN. Rproject.org/package=SpatialPosition. R package version 1.1.1. [p298]

O. González-Benito, M. Greatorex, and P. A. Muñoz-Gallego. Assessment of potential retail segmentation variables: An approach based on a subjective MCI resource allocation model. Journal of Retailing and Consumer Services, 7(3):171-179, 2000. URL https: //doi .org/10.1016/S0969-6989(99)00026-0. [p303]

GRASS Development Team. Geographic Resources Analysis Support System (GRASS GIS) Software, Version 7.0. Open Source Geospatial Foundation, 2015. URL http://grass. osgeo . org. [p316]

J. Güssefeldt. Zur Modellierung von räumlichen Kaufkraftströmen in unvollkommenen Märkten. Erdkunde, 56(4):351-370, 2002. URL https://doi .org/10.3112/erdkunde.2002.04.02. [p299, 300, 301, 316]

D. L. Huff. Determination of Intra-Urban Retail Trade Areas. University of California, 1962. [p299, 300, 303, 308, 309, 312]

D. L. Huff. A probabilistic analysis of shopping center trade areas. Land Economics, 39(1):81-90, 1963. URL https://doi .org/10.2307/3144521. [p299]

D. L. Huff. Defining and estimating a trading area. Journal of Marketing, 28(4):34-38, 1964. URL https://doi.org/10.2307/1249154. [p299]

D. L. Huff and R. R. Batsell. Conceptual and operational problems with market share models of consumer spatial behavior. Advances in Consumer Research, 2:165-172, 1975. [p299]

D. L. Huff and B. M. McCallum. Calibrating the Huff Model using ArcGIS Business Analyst. ESRI White Paper, September 2008, 2008. URL https://www.esri.com/library/whitepapers/pdfs/ calibrating-huff-model.pdf. [p298, 302, 303, 304]

P. Jia, I. M. Xierali, and F. Wang. Evaluating and re-demarcating the Hospital Service Areas in Florida. Applied Geography, 60(4):248-253, 2015. URL https://doi.org/10.1016/j.apgeog. 2014.10.008. [p298]

D. Kahle and H. Wickham. Ggmap: Spatial visualization with ggplot2. The R Journal, 5(1):144-161, 2013. URL http://journal.r-project.org/archive/2013-1/kahle-wickham. pdf. [p306]

C. Kanhäußer. Modellierung und Prognose von Marktgebieten am Beispiel des Möbeleinzelhandels. In R. Klein and J. Rauh, editors, Analysemethodik und Modellierung in der geographischen Handelsforschung, volume 13 of Geographische Handelsforschung, pages 75-109. L.I.S., 2007. [p299, 308]

R. Klein. Der Lebensmittel-Einzelhandel im Raum Verden - Räumliches Einkaufsverhalten unter sich wandelnden Bedingungen, volume 8 of Flensburger Arbeitspapiere zur Landeskunde und Raumordnung. Universität Flensburg, 1988. [p300, 301]

A. Kubis and M. Hartmann. Analysis of location of large-area shopping centres. a probabilistic gravity model for the Halle-Leipzig Area. Jahrbuch für Regionalwissenschaft, 27(1):43-57, 2007. URL https://doi.org/10.1007/s10037-006-0010-3. [p303, 304,321]

R. D. Luce. Individual Choice Behavior: A Theoretical Analysis. John Wiley \& Sons, 1959. [p299]

G. Löffler. Market areas - a methodological reflection on their boundaries. GeoJournal, 45(4):265-272, 1998. URL https://doi.org/10.1023/A:1006980420829. [p298]

W. G. Manning and J. Mullahy. Estimating log models: To transform or not to transform? Journal of Health Economics, 20(4):461-494, 2001. URL https: //doi .org/10. 1016/s0167-6296(01)00086-8. [p308, 321]

M. Marinov and D. Czamanski. Normative issues in the organization of modern retailers in Israel. GeoJournal, 77(3):383-398, 2012. URL https://doi .org/10.1007/s10708-010-9394-2. [p300]

M. Nakanishi and L. G. Cooper. Parameter estimation for a Multiplicative Competitive Interaction Model: Least squares approach. Journal of Marketing Research, 11(3):303-311, 1974. URL https: //doi.org/10.2307/3151146. [p299, 300, 302, 303, 321]

M. Nakanishi and L. G. Cooper. Simplified estimation procedures for MCI models. Marketing Science, 1(3):314-322, 1982. URL https://doi .org/10.1287/mksc.1.3.314. [p299, 303] 
T. Orpana and J. Lampinen. Building spatial choice models from aggregate data. Journal of Regional Science, 43(2):319-347, 2003. URL https://doi .org/10.1111/1467-9787.00301. [p300]

M. Pavlis, L. Dolega, and A. Singleton. The huff-tools package (version 0.6). Technical Report (PDF), 2014. URL https://github.com/alexsingleton/Huff-Tools/blob/master/huff-toolsvignette. pdf. [p298]

R. C. Perales. Consumer Choice in Competitive Location Models. Universitat Pompeu Fabra, 2002. URL http://www.tdx.cat/bitstream/handle/10803/7330/trcp1de1.pdf. [p304]

J. O. Rawlings, S. G. Pantula, and D. A. Dickey. Applied Regression Analysis. Springer-Verlag, 2nd edition, 1998. [p303, 308]

W. J. Reilly. Methods for the Study of Retail Relationships, volume 4 of Studies in Marketing. Bureau of Business Research, The University of Texas, 1929. [p298]

T. Reutterer and C. Teller. Store format choice and shopping trip types. International Journal of Retail $\mathcal{E}$ Distribution Management, 37(8):695-710, 2009. URL https://doi .org/10. 1108/09590550910966196. [p312]

J.-P. Rodrigue, C. Comtois, and B. Slack. The Geography of Transport Systems. Routledge, 2006. [p298]

J. M. C. S. Silva and S. Tenreyro. The Log of Gravity. The Review of Economics and Statistics, 88(4): 641-658, 2006. URL https://doi.org/10.1162/rest. 88.4.641. [p308, 321]

R. Suárez-Vega, J. L. Gutiérrez-Acuña, and M. Rodríguez-Díaz. Locating a supermarket using a locally calibrated Huff model. International Journal of Geographical Information Science, 29(2):171-179, 2015. URL http://doi .org/10.1080/13658816.2014.958154. [p303, 321]

B. Tihi and N. Oruc. Competitive location assessment - the MCI approach. South East European Journal of Economics and Business, 7(2):379-384, 2012. URL https: //doi .org/10. 2478/v10033-012-0013-7. [p303, 304, 321]

T. Wieland. Räumliches Einkaufsverhalten und Standortpolitik im Einzelhandel unter Berücksichtigung von Agglomerationseffekten. Theoretische Erklärungsansätze, modellanalytische Zugänge und eine empirischökonometrische Marktgebietsanalyse anhand eines Fallbeispiels aus dem ländlichen Raum Ostwestfalens/ Südniedersachsens, volume 23 of Geographische Handelsforschung. MetaGIS, 2015a. [p298, 300, 302, 303, 304, 314, 321]

T. Wieland. Nahversorgung im Kontext raumökonomischer Entwicklungen im Lebensmitteleinzelhandel - Konzeption und Durchführung einer GIS-gestützten Analyse der Strukturen des Lebensmitteleinzelhandels und der Nahversorgung in Freiburg im Breisgau. Technical report, GeorgAugust-Universität Göttingen, Geographisches Institut, Abteilung Humangeographie, 2015b. URL http://webdoc. sub.gwdg. de/pub/mon/2015/5-wieland.pdf. [p316]

T. Wieland. MCI: Multiplicative Competitive Interaction (MCI) Model, 2016. URL https://CRAN. Rproject. org/package=MCI. R package version 1.3.0. [p298]

M. Wolf. Anforderungen an Einzelhandelsgutachten. In H. Konze and M. Wolf, editors, Einzelhandel in Nordrhein-Westfalen planvoll steuern!, volume 2 of Arbeitsberichte der ARL [Akademie für Raumforschung und Landesplanung], pages 114-134. ARL, 2012. [p298]

L. Yingru and L. Lin. Assessing the impact of retail location on store performance: A comparison of Wal-Mart and Kmart stores in Cincinnati. Applied Geography, 32(2):591-600, 2012. URL https: //doi.org/10.1016/j.apgeog.2011.07.006. [p300]

Thomas Wieland

Karlsruhe Institute of Technology

Institute of Geography and Geoecology

Kaiserstr. 12, 76131 Karlsruhe

Germany

thomas. wieland@kit. edu 